This item is the archived peer-reviewed author-version of:

\title{
Targeting the norepinephrinergic system in Parkinson's disease and related disorders : the locus coeruleus story
}

\section{Reference:}

Vermeiren Yannick, De Deyn Peter Paul.- Targeting the norepinephrinergic system in Parkinson's disease and related disorders : the locus coeruleus story

Neurochemistry international - ISSN 0197-0186 - Oxford, Pergamon-elsevier science Itd, 102(2017), p. 22-32

Full text (Publisher's DOI): http://dx.doi.org/doi:10.1016/J.NEUINT.2016.11.009

To cite this reference: http://hdl.handle.net/10067/1383070151162165141 


\title{
Targeting the norepinephrinergic system in Parkinson's disease and
}

\section{related disorders: the locus coeruleus story}

\author{
Yannick Vermeiren ${ }^{a, b}$, Peter P. De Deyn ${ }^{a, b, c, ~ * ~}$ \\ ${ }^{a}$ Department of Biomedical Sciences, Laboratory of Neurochemistry and Behavior, Institute \\ Born-Bunge, University of Antwerp, Universiteitsplein 1, 2610 Wilrijk, Antwerp, Belgium \\ ${ }^{\mathrm{b}}$ Department of Neurology and Alzheimer Research Center, University of Groningen and \\ University Medical Center Groningen, Hanzeplein 1, 9713 GZ Groningen, The Netherlands \\ 'Department of Neurology, Memory Clinic of Hospital Network Antwerp (ZNA) Middelheim \\ and Hoge Beuken, Lindendreef 1, 2020 Antwerp, Belgium \\ *Corresponding author
}

yannick.vermeiren@uantwerp.be

dedeyn@skynet.be

Corresponding author: Prof. Dr. Peter P. De Deyn, Laboratory of Neurochemistry and Behavior, Institute Born-Bunge, University of Antwerp, Campus Drie Eiken, Universiteitsplein 1, BE-2610 Wilrijk (Antwerp), Belgium (e-mail: dedeyn@skynet.be; telephone number: +32 3 2652620; fax number: $+32$ 3 2652618) 


\section{ABSTRACT (max. 300 words (289))}

Parkinson's disease (PD), dementia with Lewy bodies (DLB) and Parkinson's disease dementia (PDD) are related, progressive and debilitating neurodegenerative disorders with hallmark features that include a variety of motor and non-motor symptoms (behavioral, autonomic and cognitive dysfunction). For almost half a century, the motor aspects have been attributed to Lewy pathology (LP) predominantly in the substantia nigra (SN), causing a major loss of dopaminergic neurons. However, the relative success of dopaminergic replacement therapies for alleviation of solely the parkinsonian features has prompted researchers to further explore other monoaminergic strategies which may tackle all PD-related aspects. In this regard, recent evidence suggests that LP in the locus coeruleus (LC), the brain's main source of norepinephrine (NE), precedes that of the SN, and, may be one of the very first etiological events in PD. Interestingly, oxidized NE has neuroprotective properties and may even prevent the formation of toxic and higher molecular weight $\alpha$-synuclein oligomers associated with PD. Moreover, norepinephrinergic neurons directly innervate the SN, and, LC lesioning causes more severe dopaminergic cell loss and supplementary motor manifestations, as shown in preclinical research. In fact, the LC may be considered one of the main orchestrators that controls the other major monoaminergic nuclei, such as the $\mathrm{SN}$ and raphe nuclei. Apart from its regulating function, disruption of such a sustainable but vulnerable LC-NE system has been linked to the cognitive pathophysiology of dementia as well. Consequently, LC neuronal loss and the accompanying norepinephrinergic deficiency constitute an important pharmacological target for the (symptomatic) treatment of PD/DLB/PDD. This review, therefore, summarizes and discusses all relevant neurochemical research, including the intriguing link with (prodromal) dementia, several biomarker opportunities, the latest therapeutic strategies to enhance NE signaling, and, finally, some overarching comments and perspectives for future research.

\section{KEYWORDS (max. 6)}

Dementia with Lewy bodies; Brainstem nuclei; Monoamines; 3-methoxy-4-hydroxyphenylglycol (MHPG); Biomarkers; Pharmacotherapy 


\section{TABLE OF CONTENTS}

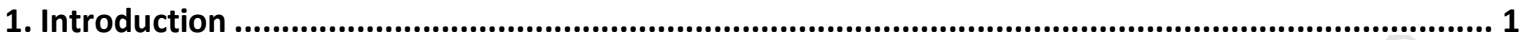

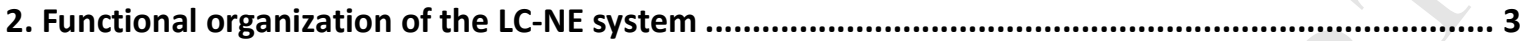

3. Anatomical evidence of early LC-NE involvement in PD and related neurodegenerative disorders .. 4

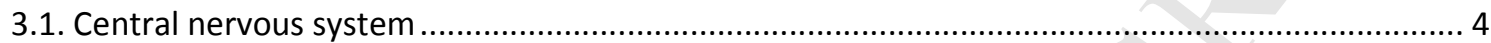

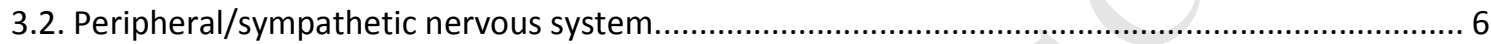

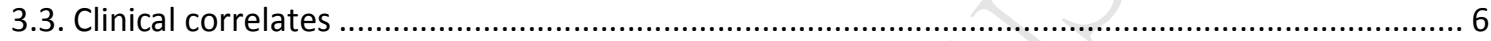

4. The LC-NE system and cognition: link with dementia .................................................................. 7

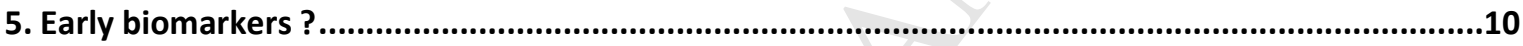

5.1. Autonomic and olfactory dysfunction: triggered by toxicants ? ............................................ 10

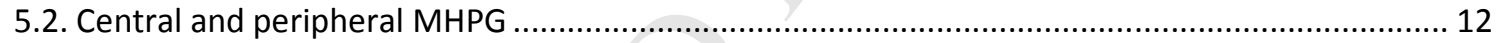

6. Therapeutic strategies to enhance NE transmission in PD and related disorders ............................13

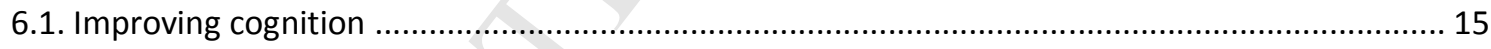

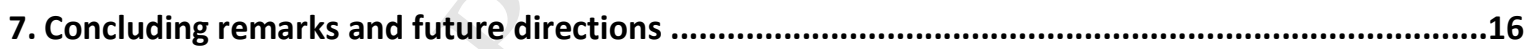

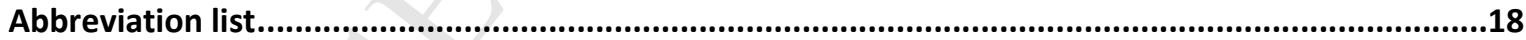

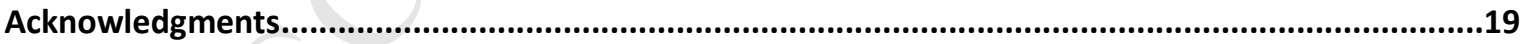

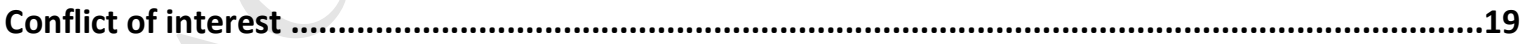

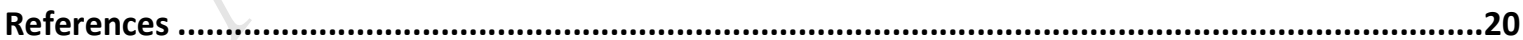




\section{MAIN TEXT}

\section{Introduction}

More than 100 neurochemicals that are known to serve as neurotransmitters have been identified in the human brain, but only few of these have a demonstrable relationship with high-level cognitive and memory processes (Augustine, 2004; Robbins and Arnsten, 2009). Of these transmitters, especially the small-molecule neuromodulators, such as biogenic amines, are an important key part. Overall, norepinephrine (NE), dopamine (DA) and serotonin (5hydroxytryptamine; $5-\mathrm{HT}$ ) are produced in relatively small-sized cell bodies in the locus coeruleus (LC), substantia nigra (SN)/ventral tegmental area (VTA) and raphe nuclei (RN), respectively, with diffusely ascending projections via long axons to virtually all parts of the brain and spinal cord. Remarkably, the LC, one of the smallest nuclei, has the most extensively branched axons and has a major role in behavioral arousal, focused attention, accurate sensory perception, task performance, stress response, and context-dependent memory consolidation and retrieval. The LC-NE system may also orchestrate pain modulation, motor control, energy homeostasis, and, control of local blood flow (sympathetic and autonomic nervous system) (Benarroch, 2009). Moreover, a dysregulated LCNE system is implicated in many pathological and psychiatric conditions, and, like the other monoamine pathways, is part of the 'ascending monoaminergic hypothesis' of dementia (Trillo et al., 2013). Latter hypothesis stems from the selective vulnerability of brainstem nuclei, and particularly monoaminergic cell groups (Parvizi et al., 2001), in neurodegenerative disease, such as Alzheimer's (AD) and Parkinson's disease (PD) (Buddhala et al., 2015; Del Tredici and Braak, 2013), leading to extensive 5-HT, DA and NE alterations across the brain. Furthermore it has been evidenced that these alterations strongly relate to the patient's behavioral profile and may even be dementia subtype-specific (Vermeiren et al., 2014, 2015, 2016).

PD is a progressive and debilitating disorder that currently affects an approximate $2 \%$ of the world's population aged 65 or older, with a general prevalence of 113 per 100,000 in the age 
category of $50-59$ up to 2,953 per 100,000 in the age group of $80+$ years in Europa/North America/Australia (Pringsheim et al., 2014). Hallmark features include motor symptoms (e.g. bradykinesia, tremor, rigidity, postural instability, freezing) accompanied with autonomic dysfunction, neurobehavioral abnormalitites (mood and cognition), sensory difficulties, and, sleep disorders (i.e. non-motor symptoms) (Jankovic, 2008). The defining histopathological aspect of PD and related disorders, including dementia with Lewy bodies (DLB) and PD dementia (PDD), is the accumulation of misfolded $\alpha$-synuclein ( $\alpha$-syn) into Lewy neurites (LN) and Lewy bodies (LB). Deposited $\alpha$-syn aggregates can be found in multiple subcortical nuclei, including the SN, LC, nucleus basalis of Meynert (nbM), as well as RN and various cortical regions (Spillantini et al., 1998). For almost six decades, the motor symptoms of PD and related disorders have mainly been attributed to Lewy pathology (LP) in the pars compacta of the SN, causing significant loss of dopaminergic neurons (Vazey and Aston-Jones, 2012). Accordingly, the relative success of DA replacement strategies solely targeting the motor impairment further emphasizes the contemporary lack of validated treatments for the spectrum of non-motor problems specified above. In this respect, the marked reduction of NE throughout PD brain remains largely neglected in much of current research, notwithstanding firm evidence that LP in the LC occurs much earlier and even to greater extent than in the SN (Del Tredici et al., 2002; German et al., 1992; Rommelfanger and Weinshenker, 2007). Furthermore, LC neuronal loss may be one of the primary pathological events of PD etiology, since norepinephrinergic neurons directly innervate the SN, facilitating burst firing, and, additional LC lesioning causes even more severe dopaminergic cell loss and supplementary motor manifestations, as shown in PD animal models (Benarroch, 2009). In fact, NE has profound effects on brain inflammation, oxidative stress (O'Donnell et al., 2012), and possesses neuroprotective properties that may even delay dementia onset as hypothesized by Rommelfanger and Weinshenker (2007).

By and large, dysregulation of the LC-NE system constitutes an important pharmacological target for the (symptomatic) treatment of PD, and, LC cell loss represents a crucial turning point in 
PD progression. Hereafter, we will discuss all relevant neurochemical research, starting with the functional organization of the LC-NE system.

\section{Functional organization of the LC-NE system}

NE is synthesized starting from its precursors L-phenylalanine and L-tyrosine. Initially, Ltyrosine is converted into L-dihydroxyphenylalanine (L-DOPA; levodopa) by tyrosine hydroxylase (TH), after which L-DOPA is converted into DA by DOPA decarboxylase, and, finally, this intermediate compound is transformed into NE by the action of DA $\beta$-hydroxylase. This final step takes place within synaptic vesicles to which DA is transported by means of the vesicular monoamine transporter. The rate-limiting enzyme of this multi-enzyme pathway is TH. Inactivation of NE occurs by the presynaptic reuptake via a selective NE transporter, followed by metabolism into 3,4dihydroxyphenylglycol by monoamine oxidase, and, accordingly, into 3-methoxy-4hydroxyphenylglycol (MHPG) by means of catechol-o-methyltransferase (Kuhar et al., 2006). Interestingly, MHPG passes the blood-brain as well as the blood-cerebrospinal fluid (CSF) barrier (Sharma et al., 1994). Consequently, MHPG constitutes a good index of central (Chase et al., 1973) and peripheral (Kessler et al., 1976) NE activity and metabolism. It is estimated that approximately $30-50 \%$ of MHPG derived in the brain is excreted via urine (Kuhar et al., 2006). Released NE acts locally at nearby synapses or distally as a paracrine hormone. This catecholamine binds to G-protein coupled receptors, including $\alpha_{1}, \alpha_{2}$ and $\beta$, each consisting of various subtypes, expressed on neurons, glia and other cell types. The excitatory $\alpha_{1}$ - and $\beta$-receptors are located mainly postsynaptically, whereas $\alpha_{2}$-subtype receptors exist both pre- and postsynaptically, and, are mainly inhibitory (Benarroch, 2009).

The LC is responsible for more than half the brain's cellular capacity of synthesized NE and comprises no more than a roughly estimated 15,000-32,000 neurons (Aston-Jones and Cohen, 2005; Espay et al., 2014). This small cluster of neurons in the upper dorsolateral pontine tegmentum of the brainstem, located adjacent to the fourth ventricle (Figure 1), has extensively branched axons that 
project to multiple cortical, subcortical, brainstem, and spinal cord nuclei, and, provides the sole source of NE to the neocortex, hippocampus, cerebellum and most of the thalamus (Aston-Jones and Cohen, 2005). LC neurons are characterized by an immense arborization. More specifically, it has been calculated that the whole brain of a rat receives $10^{8}$ norepinephrinergic terminals from a single LC neuron (Trillo et al., 2013). One such LC neuron, with an average diameter of $45 \mu \mathrm{m}$, also innervates the great majority of the microvasculature of the central nervous system (CNS) and the associated astrocytic end-feet, with, approximately, 20 meters of length of a capillary wall innervated per neuron (Pamphlett, 2014).

Generally, innervations of the LC-NE system to the prefrontal cortex, amygdala and hippocampus have a critical role not only in attention-related processes (e.g. task performance, focused alert) but also in enacting working memory, facilitating memory consolidation and retrieval, and, exploring novelty. The functional role of the LC-NE system in innervating the subcortical and brainstem structures is related to vigilance, arousal/wakefulness, REM sleep behavior and pain modulation (Benarroch, 2009; Espay et al., 2014). Regarding the peripheral autonomic nervous system, NE serves as the major neurotransmitter of sympathetic postganglionic neurons that innervate the blood vessels and heart, regulating blood pressure and heart rate (Stewart, 2012).

\section{Anatomical evidence of early LC-NE involvement in PD and related}

\section{neurodegenerative disorders}

\subsection{Central nervous system}

As reported by Braak et al. (2003) and Del Tredici and Braak (2013), six stages can be distinguished in the evolution of PD-related pathology. Inititally, at stage 1 , lesions are virtually confined to the dorsal IX/X motor nucleus (Figure 2) and/or intermediate reticular zone (medulla oblongata). In this context, LN always appear prior to LB. The LP, however, quickly spreads to more rostral structures, of which mainly the LC (Figure 3), caudal RN and gigantocellular reticular nucleus (i.e. medulla oblongata and pontine tegmentum; stage 2) become affected. During stage 3, a 
bifurcation, as it were, occurs, with on the one hand LP developing in high order relay centers of the central autonomic network (central subnucleus of the amygdala, hypothalamus and limbic circuit components), and, on the other hand, pathological lesions progress into superordinate centers of the somatomotor system, including the pedunculopontine tegmental nucleus and pars compacta of the SN/striatal circuit (i.e. midbrain lesions) (Figure 4). The temporal mesocortex including the transentorhinal region and allocortex (CA2-plexus) become involved during stage 4, after which lesions in high order sensory association areas of the neocortex and prefrontal cortex (stage 5), and, finally, additional lesions across nearly the entire neocortex (i.e. premotor areas, primary motor field, first order sensory association and primary sensory areas) become apparent. It is of note that the intraneuronal $\alpha$-syn accumulation is also found during stages 1 and 2 within the olfactory bulbs, from where the LP spreads to secondary olfactory structures, and, eventually, to the thalamus and neocortex (Doty, 2012). As mentioned earlier, $\alpha$-syn burden in the LC not only precedes (stage 2), but may even be of greater magnitude than that of the SN (stage 3) in PD, DLB and PDD. During stages 2 and 3, LP gradually develops in different portions of the entire spinal cord as well (dorsal horn layer 1, somatomotor neurons and Onuf's motoneurons layer 9) (Del Tredici and Braak, 2012).

In PD brain, there is an extensive neuronal loss in the LC alongside the entire length of its structure. This leads to extensive norepinephrinergic deafferentiation, and, eventually, loss of axons projecting from LC neurons (Espay et al., 2014). This is in contrast with AD and Down syndrome (DS), where LC neuronal loss is limited to a more rostral portion only, that mainly projects to a selective subset of prefrontal and cortical neurons (German et al., 1992). In addition, it has been shown in a postmortem study investigating 125 brains of older adults without a clinical diagnosis of PD, that the neuronal density primarily in the LC was associated with age-related (mild) parkinsonian symptoms, making it an earlier target for neurodegeneration than the SN (Buchman et al., 2012). Likewise, patients with incidental DLB, namely those lacking clinical features of PD in about $10 \%$ of the population aged over 60 even though LB are present (i.e. the premotor phase), have a lower neuronal density in the LC than in the pars compacta of the SN (Dickson et al., 2008). 


\subsection{Peripheral/sympathetic nervous system}

It has been suggested that postganglionic sympathetic neurons might be the first ones to become affected by $\alpha$-syn deposits, which is in line with the theory that PD pathology originates outside the CNS (Kaufmann et al., 2004). Postmortem studies also revealed that incidental DLB patients had a depletion of TH-containing axons in the myocardium, and, in vivo cardiac scintigraphy in PD subjects using metaiodobenzylguanidine (MIBG) showed a characteristic reduction in tracer uptake, particularly in the myocardium of the left cardiac ventricle (Hakusui et al., 1994; Slaets et al., 2015; Takatsu et al., 2000). Latter findings point in the direction of significant alterations of norepinephrinergic innervation of the heart, already in the early premotor PD stages, which is in line with the occurrence of LP in the dorsal nucleus of the vagus nerve in stage 1, from which, hypothetically, LP may also spread to the peripheral nervous system. After all, Brundin et al. (2008) evidenced that $\alpha$-syn can be transferred across synapses (transneuronal expansion) and spread within postsynaptic cells (intra-axonal transport). Moreover, as extensively studied by Del Tredici and Braak (2012), during stage 2, the intermediolateral nucleus containing the autonomic motor neurons also becomes affected, from where the postganglionic neurons during stage 3 gradually develop LP.

\subsection{Clinical correlates}

Depending on the various stages (1-6), the accompanied degree of LC neuronal loss, and, overall NE deficiency in the CNS and periphery, a variety of clinical symptoms can be observed. Broadly speaking, autonomic and olfactory disturbances are among the first indications in PD (stages 1-2), followed by sleep and motor disturbances (stages 3-4), and, in the later phases of the disease, emotional and cognitive disturbances (stages 5-6) (Halliday et al., 2011).

Particular signs and symptoms of the autonomic failure consist of postural lightheadedness, idiopathic orthostatic hypotension (syncope), constipation, bladder and erectile dysfunction, subnormal increases of heart rate during exercise (chronotropic incompetence), and, fatigue, which has also been linked to myocardial sympathetic denervation as measured by MIBG scintigraphy 
(Kaufmann et al., 2004; Nakamura et al., 2011). More recently, Seidel et al. (2015) demonstrated that

LB and LN can also be present in all cranial nerve nuclei, such as premotor/oculomotor, precerebellar, and vestibular brainstem nuclei, as well as $L N$ in all brainstem fiber tracts, of PD and DLB patients. These novel findings may account for a large variety of less well-explained symptoms (e.g. gait and postural instability, falls, ingestive and oculomotor dysfunctions, impaired balance). The other motor and non-motor symptoms that evolve during stages $3-6$, are predominantly related to LC neurodegeneration and are summarized in Table 1.

Interestingly, Delaville and colleagues (2012) noted a significant decrease in locomotor activity in 6-hydroxydopamine-lesioned (i.e. DA depleted) rats - similar to sham-lesioned rats only receiving NE depleting drugs - if compared to sham-lesioned rats not undergoing any monoamine depletion procedure. As for the non-motor symptoms, anxiety-like states were introduced in 6hydroxydopamine-lesioned rats after additional depletion of 5-HT or NE, whereas anhedonia and depressive-like behavior required additional depletion of both 5-HT and NE. The authors thus provided preclinical evidence for exacerbation of non-motor (behavioral) symptoms in case of significant additional losses of 5-HT and/or NE, stressing the importance of substantially altered interactions between all three monoaminergic systems in PD.

\section{The LC-NE system and cognition: link with dementia}

It always has been generally assumed that cognitive changes in PD are the result of LB infiltrating into the (neo)cortical brain areas (Braak et al., 2005). However, the much earlier involvement of the LC (stage 2) and the fact that the onset of LC-NE pathology is postulated to occur more than 10 years before the clinical diagnosis of PD (Hawkes et al., 2010), suggest that the earliest executive dysfunctions may, at least partly, be attributed to norepinephrinergic deficiencies. Additional evidence comes from the paracrine effects of NE via non-junctional varicosities on astrocytes and microglia, which suppress neuroinflammation (O'Donnell et al., 2012), an indispensable part of PD pathophysiology (More et al., 2013). In addition, NE displays 
neuroprotective properties (Espay et al., 2014). More specifically, there might be a compensatory role of the LC-NE system in early PD, since LC lesioning in squirrel monkeys that subsequently received MPTP injections not only exacerbated dopaminergic cell loss of the $\mathrm{SN}$, but also impaired the normal recovery of parkinsonian signs days after cessation of MPTP administration (Mavridis et al., 1991). Similarly, NE-rich regions seemed to be spared from dopaminergic cell loss, as was shown in more than 20 brain regions by a postmortem PD study of Tong et al. (2006). We, therefore, may say that the LC is the orchestrator that oversees dopaminergic functioning of SN neurons, thereby managing the survival of these neurons when experiencing various non-physiological stress indicators, such as $\alpha$-syn deposits.

Another important reason why the LC-NE system might be closely related to the progressive cognitive worsening in early/premotor PD and further disease stages, is its efferent projections to the amygdala, prefrontal cortex and hippocampus, to which the LC is the only norepinephrinergic source provider (Foote et al., 1983). Experimental studies indicated that NE via the $\beta$-receptors is involved in long term potentiation in the hippocampus, and, that this synaptic plasticity effect can be influenced by the behavioral state of arousal (e.g. novelty seeking) (Sara, 2009). For example, the activity of the LC increased significantly, as well as its connectivity to the amygdala, during magnetic resonance imaging when performing emotional face retrieval tasks (Sterpenich et al., 2006). Receptor binding studies in AD and DLB brain also demonstrated that in both dementias, $\alpha_{1 D^{-}}$and $\alpha_{2 C^{-}}$-adrenoreceptors were downregulated in the hippocampus, together with plastic changes of LC neuronal loss, including increased TH expression, and, sprouting of LC dendrites and axons to the hippocampus (Szot et al., 2006). These marked norepinephrinergic changes were even more prominent in DLB, and the authors proposed that, even though there were LB in addition to plaques and tangles, compensatory changes occurred in remaining LC neurons. Furthermore, in AD, but not PD, German et al. (1992) found a significant correlation between the magnitude of LC cell loss and disease duration. As mentioned above, the LC in PD/DLB/PDD undergoes much more severe neurodegeneration compared to $A D$, where there still is a relative sparing of the caudal LC portion, even in advanced 
cases (German et al., 1992). Latter finding agrees with the statement that PD really is a LC-specific disease entity, probably leading to a range of substantial non-motor symptoms already in the very early phases after less substantial LC neurodegeneration than in AD.

From a neurochemical point of view, recent evidence suggests that oxidized catecholamines, particularly oxidized NE, effectively retain and stabilize $\alpha$-syn in a soluble, monomeric form so that it becomes incapable of generating the toxic oligomers associated with PD (Fischer and Matera, 2015). Even more interesting, these authors further observed a $20-40 \%$ decrease in fibril content of an $\alpha$ syn aggregate solution in the presence of oxidized NE and DA, stressing that catecholamines can disaggregate existing fibrils and have peculiar neuroprotective properties indeed. These results implicate that NE is a very important modulating compound that may be essential for physiological $\alpha$ syn processing. Consequently, there certainly appears to be a significant link between an affected LCNE system following LP, and PD, eventually leading to a more characteristic dementia phenotype when pathology progresses (i.e. DLB or PDD, depending on when first cognitive symptoms emerge; 1year rule (McKeith et al., 2005)). In line with this observation, Taylor et al. (2014) developed a mouse model with reduced expression of the vesicular monoamine transporter, leading to substantial reductions in striatal and cortical DA ( $94 \%$ and $57 \%$, respectively), cortical NE $(54 \%)$, as well as cardiac NE (97\%), mimicking the neurochemical state in PD to a certain degree. Surprisingly, losses were accompanied by increased conversion of DA and NE into their deaminated metabolites, loss of norepinephrinergic innervation in the cortex, and, a progressive degeneration of the LC that preceded the pars compacta of the SN. In contrast, the VTA remained unaffected. The authors thus demonstrated that insufficient catecholamine storage can cause spontaneous degeneration of susceptible norepinephrinergic neurons.

Finally, it is important to note that LC innervation activates acetylcholine (ACh) neurons in the nbM of the basal forebrain (Jones, 2004), so that pathology in the LC in early PD may significantly contribute to decreased cortical ACh levels too (Vazey and Aston-Jones, 2012). Even though both the cholinergic and norepinephrinergic neurotransmitter system are critically involved in attention 
processes and cognitive flexibility, only norepinephrinergic, but not cholinergic, denervation causes impairment in the ability to shift attention (McGaughy et al., 2008). It seems NE mediates unexpected uncertainty while ACh mediates expected uncertainty. It then appears that cholinergic brain changes are more pertinent to the later stages of PD, whereas the lessened ability to refocus attention in the first PD phases could be more ascribed to loss of norepinephrinergic neurons (Vazey and Aston-Jones, 2012). This conclusion, again, suggests the early involvement of a damaged LC-NE system in inducing cognitive dysfunction in premotor PD patients.

The following section will briefly discuss how the first symptomatic indications due to LC pathology and altered NE or MHPG levels may provide an opportunity to accurately detect preclinical PD.

\section{Early biomarkers ?}

\subsection{Autonomic and olfactory dysfunction: triggered by toxicants?}

As proposed previously, autonomic failure may be the initial presentation of PD and related disorders, whereas at present, it is more acknowledged as a late complication (Kaufmann et al., 2004). Given the topography and nature of LP spread in the CNS, since $\alpha$-syn spreads transneuronally in a prion-like fashion (Brundin et al., 2008), originating in the dorsal nucleus of the vagus nerve in the medulla oblongata (stage 1), and, from there progressing rostrally as well as caudally, peripheral autonomic (norepinephrinergic) neurons may well be affected years beforehand. Only thereafter, stage 2-impairment of the LC may become evident (Braak et al., 2003). Nevertheless, since the LC also has strong connections with sympathetic preganglionic neurons of the spinal cord, controlling autonomic functions (Samuels and Szabadi, 2008), it is thus implicated that the locus may be indirectly involved in the prodromal phases of PD. For instance, infrequent bowel movements have been associated with an increased risk of future PD (Abbott et al., 2001), and, MIBG scintigraphy or myocardial PET imaging with 6-[(18)F]fluorodopamine showed that there is a significant loss of NE uptake in cardiac postganglionic sympathetic neurons in early PD (Goldstein et al., 2000; Takatsu et 
al., 2000) and DLB patients (Watanabe et al., 2001). Watanabe et al. (2001), Takatsu et al. (2000), and, Slaets et al. (2015) also denoted that MIBG scintigraphy can be a relevant biomarker tool for the differential diagnosis between PD/DLB and AD or healthy controls.

On the other hand, significant smell dysfunction has also been recognized as an early PD feature with a prevalence of approximately $90 \%$ of sporadic cases (Doty et al., 1988a). Interestingly, smell loss correlated significantly with cardiac sympathetic denervation (Lee et al., 2006), contributing to the assumption that PD is a systemic disease with major autonomic impairment. It is intriguing that, as mentioned earlier, $\alpha$-syn pathology infiltrates into the olfactory bulbs in the earliest disease stages (1 to 2 ), from where it later proceeds to the cortical regions. Moreover, $\alpha$-syn pathology may be further initiated in the periphery via input from the olfactory epithelium or vagal inputs from the stomach, perhaps involving xenobiotic factors. Because the parasympathetic innervation of the stomach and intestines is normally provided by the dorsal motor nucleus of the vagus nerve, constipation is also very common in PD (Halliday et al., 2011). Olfactory dysfunction can be attributed to lesioning of the LC, as well as the SN and RN (Doty, 2012). Co-involvement of $\alpha$-syn pathology in the LC and primary olfactory structures was seen in 73\% of PD cases (Del Tredici et al., 2002). However, patients lacking DA $\beta$-hydroxylase seem to have a relatively normal olfactory function, and, the same applies to rats in which NE content has been depleted in the olfactory bulb using 6-hydroxydopamine (Doty et al., 1988b). Latter findings point to a more neuroprotective role of the LC in preserving olfaction. Together with the evidence that the olfactory tubercle receives dopaminergic input from the VTA and that significant correlations have been found between olfactory test scores and DA transporter activity in the nigrostriatal region (Deeb et al., 2010; Wong et al., 2010), it may rather be that dopaminergic deficiencies could be a determinant of this peculiar feature of PD (Doty, 2012) - albeit under control of the LC. Doty (2012) further describes that olfactory dysfunction accurately differentiates PD subjects from controls, and, patients suffering from progressive supranuclear palsy, corticobasal degeneration or multiple system atrophy, but not AD or DS subjects. 
The LC in general, as well as the olfactory epithelium, are very susceptible to toxicants. It has been stated that, for instance, air pollution-related neurotoxins, including nanoparticles found in diesel exhaust (xenobiotics) entering the nose, may promote inflammatory processes and PD-like pathology in the olfactory bulb and other forebrain structures (Doty, 2012). Similarly, Pamphlett et al. (2014) hypothesize that environmental toxicants, such as metallic mercury or DSP4, may enter the LC selectively, aided by the extensive exposure of LC neurons to CNS capillaries, and, cause a massive NE depletion. The link between environmental toxicants, LC degeneration, PD and other neurodegenerative disorders, however, necessitates further investigation.

\subsection{Central and peripheral MHPG}

Could a biomarker linked to the systemic decline in NE neurotransmission provide an early warning for PD? In this regard, the main metabolite of NE, i.e. MHPG, readily passes the blood-brain and blood-CSF barrier (Sharma et al., 1994). For that reason, MHPG constitutes a good index of central (Chase et al., 1973) and peripheral (Kessler et al., 1976) NE activity and metabolism, thereby reflecting LC functioning to a certain degree. A handful of studies so far studied this matter (Dekker et al., 2015; Herbert et al., 2014; Vermeiren et al., 2015). Firstly, it appears that the addition of CSF MHPG to traditional CSF AD biomarkers $\left(\beta\right.$-amyloid $_{1-42}$, total tau, tau phosphorylated at threonine 181) improved the differentiation of AD from DLB patients (Herbert et al., 2014). Moreover, neurochemical research in DS subjects evidenced that peripheral serum MHPG levels even predicted conversion to $A D$, with a more than 10 -fold increased risk of developing dementia if levels were below $21.5 \mathrm{ng} / \mathrm{ml}$ (Dekker et al., 2015). Subsequently, our own group recently observed a significant decrease in MHPG levels across the entire DLB brain if compared to similar regions of AD brain (Vermeiren et al., 2015), and, likewise, Cash et al. (1987) found that MHPG and NE levels were significantly decreased in the LC, albeit in demented PD subjects only. Finally, we recently finished the neurochemical analyses of paired serum and CSF samples of $A D, D L B$, frontotemporal dementia (FTD), age-matched control, and, young control subjects, all who had CSF AD biomarker data as well 
(unpublished results). Our results confirm the findings of Herbert et al. (2014) that CSF NE and CSF/serum MHPG are among the most predictive markers in addition to CSF AD biomarkers indeed. More specifically, the addition of CSF MHPG to the diagnostic AD model not only considerably improved the discrimination (sensitivity and specificity) of DLB from AD, but also CSF/serum MHPG and CSF NE improved the discrimination of DLB from FTD, and, AD from FTD/controls, respectively. Results suggest that dementia subtype-specific lesioning of the LC may have profound effects on downstream CSF NE/MHPG and even peripheral MHPG levels (unpublished results), making it a potentially promising biomarker.

Conversely, there is a great need for studies that include patients with very early PD besides advanced PD (with or without mild cognitive impairment (MCI)), DLB/PDD, AD, FTD and age-matched controls to further look into the (added) biomarker potential of peripheral MHPG levels in serum. The norepinephrinergic effects in CSF or blood due to autonomic dysfunction in PD require further scrutiny accordingly. Caution is also advised when interpreting the results of CSF MHPG levels, particularly since MHPG is distributed across the entire spinal cord tissue $(70-80 \%)$, and the spinal cord may also be involved in clearance of this metabolite, possibly making CSF MHPG an uncertain indicator of central NE metabolism in the brain or LC (Kessler et al., 1976).

\section{Therapeutic strategies to enhance NE transmission in PD and related disorders}

We propose that LC loss represents a crucial turning point in PD progression, and that strategies aiming at restoring NE neurotransmission may have important therapeutic potential for improvement of the motor and non-motor manifestations, including cognitive impairment. Overall, an increase of NE signaling can be effectuated by three strategies: (i) increase of NE content in the synaptic cleft by administering a selective NE reuptake inhibitor (NRI); (ii) increase of NE synthesis; (iii) increase of NE release by antagonizing remaining presynaptic (inhibitory) $\alpha_{2}$-adrenoreceptors (autoreceptors) (Espay et al., 2014). The second strategy consists of treatment with levodopa or droxidopa. Droxidopa is a NE precursor molecule that passes the blood-brain barrier by a facilitated 
neutral amino acid transport mechanism, whereas levodopa administration, although this compound is a DA precursor molecule primarily purposed to increase DA content, increases NE turnover in the central and peripheral nervous system as a secondary effect (Dayan and Finberg, 2003). Table 2 summarizes all (completed) clinical trials so far related to these three strategies, intended to improve NE signaling and thus motor/non-motor deficits.

Another noteworthy point regarding the potential enhancement of NE transmission in PD by increasing NE synthesis, is the use of monoamine oxidase (MAO) A or B inhibitors. Although their effects on NE synthesis have not thoroughly been investigated so far in PD patients, these compounds, such as clorgyline (irreversible MAO-A inhibitor), rasagiline or selegiline (MAO-B inhibitors), of which latter two have promising neuroprotective properties, have shown to significantly increase not only DA but also NE content in the medium of rat pheochromocytoma PC12 cells, as well in the PC12 cells themselves (Goldstein et al., 2016). In several clinical trials, rasagiline, both as a monotherapy or as adjunctive therapy to levodopa in early PD, has proven beneficial in delaying the need for antiparkinsonian drugs and increasing the Unified Parkinson's Disease Rating Scale (UPDRS) scores (Rascol et al., 2005; 2011). The combined effects of an antidepressant and rasagiline on non-motor symptoms in de novo PD patients also showed less worsening of depression, cognition, fatigue, and daytime sleepiness (Smith et al., 2015).

Furthermore, it is of interest that, apart from pharmacotherapies, a growing body of evidence suggests that the subthalamic nucleus (STN), which is targeted by means of deep brain stimulation (DBS) and accordingly improves motor performance, is connected to the LC, and, that STN neuronal activity is under control of $\alpha_{1}$ - and $\alpha_{2}$-adrenoreceptors (Faggiani and Benazzouz, 2016). Additionally, clonidine, an $\alpha_{2}$-adrenoreceptor agonist, diminished the beneficial effects of STN-DBS in PD patients suffering from akinesia (Albares et al., 2015). Importantly, this study indicates that the efficiency of this surgically implanted neurostimulator is NE-dependent, and further supports the decisive role of the LC-NE system. It also implies that in PD patients who only have limited beneficial 
effects of STN-DBS, a combination of this 'golden standard' technique and a norepinephrinergic agent, such as an $\alpha_{2}$-adrenoreceptor antagonist, may be considered.

Hereafter, we will only focus on encouraging NE pharmacotherapies that may improve or restore cognition in PD.

\subsection{Improving cognition}

So far, only a handful of studies investigated whether NE-modifying agents could enhance cognition. The three major drugs in this context, are, clonidine, atomoxetine, and droxidopa.

Firstly, clonidine seems to have limited effects on memory performance. Riekkinen et al. (1999) administered clonidine in 16 mild and 16 severe PD patients. The authors concluded that the drug facilitated spatial working memory in patients who were on, as well as off dopaminergic medication (Table 2). The effects were greater in the severe PD subgroup. However, no improvements were noticed regarding attentional set shifting or visual recognition memory performance.

Secondly, atomoxetine administration (an NRI indicated for attention deficit hyperactivity disorder) has had various outcomes. For instance, a small pilot open-label study of 12 PD patients reported significantly improved outcome measures after eight weeks of treatment, namely executive dysfunction and frontal behavior. Observed adverse events were sleep and gastrointestinal disturbances, and, hypomania (Marsh et al., 2009). Similarly, Weintraub et al. (2010) studied the effects of 8-week atomoxetine treatment in 55 PD subjects, specifically looking at depression (Table 2). Surprisingly, there was no alleviation of depressive symptoms, even though global cognition and daytime sleepiness, which were secondary outcome measures, significantly improved. Both studies also mentioned that atomoxetine was well-tolerated. Contrarily, a 12-week randomized, placebocontrolled trial which has recently been completed, observed no effects of atomoxetine (ClinicalTrials.gov identifier NCT01738191). This study assessed the cognitive outcome measures in 30 early-onset PD patients with $\mathrm{MCl}$ as an early phase II trial. However, there only was a subjective 
improvement noticeable (by patients), but not objective, in executive functioning. The investigators further concluded that atomoxetine is unlikely to enhance day-to-day functioning in this PD-MCI population (https://www.michaeljfox.org/foundation/grant-detail.php?grant id=1037; unpublished results). Nonetheless, one should keep in mind that there may well be some degree of heterogeneity of norepinephrinergic cell loss among PD patients, which might explain the various outcomes of NE enhancing drugs, such as atomoxetine, in these trials.

Finally, droxidopa, which has been licensed by the Food and Drug Administration (FDA) in February 2014 for the treatment of symptomatic neurogenic orthostatic hypotension (NOH) in PD among others (Kaufmann et al., 2015), and, is used off-label (apart from Japan (Espay et al., 2014)) to treat freezing of gait (FOG), only recently gained attention as a powerful candidate that might alleviate cognitive dysfunction. At present, an 11-week, double-blinded, placebo-controlled phase II study in progress with an estimated completion date of December 2017 investigates droxidopa effects on FOG and cognitive functioning in approximately 20 enrolled PD-MCl subjects (NCT02066571).

\section{Concluding remarks and future directions}

The evidence piles up that LC-NE deficiency is of greater magnitude, occurs earlier, and, shows stronger correlation with disease severity than the dopaminergic deficiency in PD and related disorders. LC neuronal loss seems to surpass that of the pars compacta of the SN, even in the prodromal phases. Clinical trials spanning the last five years have also shown that NE-enhancing treatments significantly improve the motor and non-motor manifestations in PD, including cognition, although trials, in this respect, are currently ongoing. Except the symptomatic benefits, LC-NEenhancing therapies might also comprise an important disease-modifying potential, given that oxidized NE effectively prevents the formation of oligomeric forms of $\alpha$-syn (Fischer and Matera, 2015), emphasizing its neuroprotective properties. One has to bear in mind, however, that PD is a clinically heterogeneous disorder that affects multiple neurotransmitter systems, even though, from 
a neuropathological point of view, the first lesioning occurs in the brainstem (vagus nerve; N. X.) and LC (stages 1-2). This involves the caudal RN as well (stage 2), with whom the LC has strong and reciprocal connections. Perhaps the two main monoaminergic orchestrators in PD may well be the LC and RN. An ongoing clinical trial relating to this matter presently evaluates the safety, tolerability and efficacy of a dual $5-\mathrm{HT}_{6} / 5-\mathrm{HT}_{2 \mathrm{~A}}$ antagonist, named SYN120, in PDD (phase Ila; Biotie Therapies Inc. NCT02258152). Tackling both systems, by e.g. administering a selective serotonin-norepinephrine reuptake inhibitor (SNRI), may therefore be appropriate (Table 2). Contrariwise, profound loss of NE and DA neurons, which are both required for the mechanism of action of NRIs such as atomoxetine, and, levodopa, respectively, limits these types of strategies in which pharmacotherapies are combined (e.g. SNRI combined with levodopa). Additionally, De Deurwaerdère et al. (2016) emphasized that levodopa favors serotonergic rather than dopaminergic projections, since levodopa can be transformed into DA in 5-HT neurons equally (extra-striatal DA release), and, selective serotonin reuptake inhibitors (SSRIs) reduce levodopa-stimulated DA release via $5-\mathrm{HT}_{1 \mathrm{~A}}$ receptors. For that reason, such therapeutic strategies rather seem conflicting.

To ensure success of future clinical trials, studies should include patients with very mild PD (with/without cognitive disorder), but also severe PD, and, even other movement disorders, or, dementias, such as AD or FTD alone or in combination with amyotrophic lateral sclerosis, given that there might be a common neurochemical basis and similar order of neurochemical events in proteinopathies in general. Not only the effects of carefully-selected combination therapies, but also the additional effects of NE-enhancing drugs on STN-DBS should be carefully evaluated. In fact, largescale epidemiological and toxicological studies that study why LP originates in brainstem nuclei, may ultimately lead to a narrowed search for novel strategies of PD prevention and treatment. Finally, the biomarker potential of central and peripheral MHPG levels in relationship with autonomic dysfunction, whether or not in addition to traditional or future (CSF) AD biomarkers, provides a valuable approach to validate novel and easily accessible discriminative compounds in undiagnosed 
PD - albeit dietary, spinal cord, and, environmental effects on NE metabolism should be equally investigated.

\section{Abbreviation list}

5-HT: $\quad$ 5-hydroxytryptamine (serotonin)

$\alpha$-syn: $\quad \alpha$-synuclein

L-DOPA: levodopa or L-dihydroxyphenylalanine

ACh: $\quad$ acetylcholine

AD: $\quad$ Alzheimer's disease

CNS: $\quad$ central nervous system

CSF: cerebrospinal fluid

DA: dopamine

DBS: deep brain stimulation

DLB: dementia with Lewy bodies

DS: Down syndrome

FTD: $\quad$ frontotemporal dementia

FOG: $\quad$ freezing of gait

LB: $\quad$ Lewy bodies

LC: locus coeruleus

LN: Lewy neurites

LP: Lewy pathology

MAO: monoamine oxidase

$\mathrm{MCl}$ mild cognitive impairment

MHPG: 3-methoxy-4-hydroxyphenylglycol

MIBG: metaiodobenzylguanidine

nbM: nucleus basalis of Meynert 


$\begin{array}{ll}\text { NE: } & \text { norepinephrine } \\ \text { NOH: } & \text { neurogenic orthostatic hypotension } \\ \text { NRI: } & \text { norepinephrine reuptake inhibitor } \\ \text { PD: } & \text { Parkinson's disease } \\ \text { PDD: } & \text { raphe nuclei } \\ \text { RN: } & \text { substantia nigra } \\ \text { SN: } & \text { selective serotonin reuptake inhibitor } \\ \text { SSRI: } & \text { subthalamic nucleus } \\ \text { STN: } & \text { tyrosine hydroxylase } \\ \text { TH: } & \text { unified Parkinson's disease rating scale } \\ \text { UPDR: } & \end{array}$

\section{Acknowledgments}

The work of all included authors was supported by the Research Foundation-Flanders (FWO), Interuniversity Poles of Attraction (IAP Network P7/16) of the Belgian Federal Science Policy Office, Methusalem excellence grant of the Flemish Government, agreement between Institute Born-Bunge and University of Antwerp, the Medical Research Foundation Antwerp, the Thomas Riellaerts research fund, Neurosearch Antwerp, and the Alzheimer Research Center of the University Medical Center Groningen (ARCG-UMCG).

The authors gratefully acknowledge Mrs. Inge Bats (Biobank, Institute Born-Bunge) for her excellent photographical support (figures 1-4), and, Em. Prof. Dr. Jean-Jacques Martin (Biobank, Institute Born-Bunge) for his experienced neuropathological assistance (figure legends).

\section{Conflict of interest}

The authors herein declare no actual or potential conflicts of interest. 


\section{References}

Abbott, R.D., Petrovitch, H., White, L.R., Masaki, K.H., Tanner, C.M., Curb, J.D., Grandinetti, A., Blanchette, P.L., Popper, J.S., Ross, G.W., 2001. Frequency of bowel movements and the future risk of Parkinson's disease. Neurology 57, 456-462.

Albares, M., Thobois, S., Favre, E., Broussolle, E., Polo, G., Domenech, P., Boulinguez, P., Ballanger, B., 2015. Interaction of noradrenergic pharmacological manipulation and subthalamic stimulation on movement initiation control in Parkinson's disease. Brain Stimul. 8, 27-35.

Aston-Jones, G., Cohen, J.D., 2005. An integrative theory of locus coeruleus-norepinephrine function: adaptive gain and optimal performance. Annu. Rev. Neurosci. 28, 403-450.

Augustine, G.J., 2004. Chapter 6: Neurotransmitters and their receptors, in: Purves, D., Augustine, G.J., Fitzpatrick, D., Hall, W.C., LaMantia, A.-S., McNamara, J.O., Williams, S.M. (Eds.), Neuroscience 3rd Edition. Sinauer Associates Inc., Sunderland, MA, pp. 129-164.

Bédard, M.A., el Massioui, F., Malapani, C., Dubois, B., Pillon, B., Renault, B., Agid, Y., 1998. Attentional deficits in Parkinson's disease: partial reversibility with naphtoxazine (SDZ NVI-085), a selective noradrenergic alpha 1 agonist. Clin. Neuropharmacol. 21, 108-117.

Benarroch, E.E., 2009. The locus ceruleus norepinephrine system: functional organization and potential clinical significance. Neurology 73, 1699-1704. 
Biaggioni, I., Freeman, R., Mathias, C.J., Low, P., Hewitt, L.A., Kaufmann, H., 2015. Randomized withdrawal study of patients with symptomatic neurogenic orthostatic hypotension responsive to droxidopa. Hypertension 65, 101-107.

Bonuccelli, U., Meco, G., Fabbrini, G., Tessitore, A., Pierantozzi, M., Stocchi, F., Ceravolo, R., Caltagirone, C., Silvestrini, M., Morgante, F., Ruggieri, S., Avanzino, L., Guadagna, M., Dell'Agnello, G., Rossi, A., Spezia, R., Mancini, M., 2012. A non-comparative assessment of tolerability and efficacy of duloxetine in the treatment of depressed patients with Parkinson's disease. Expert. Opin. Pharmacother. 13, 2269-2280.

Braak, H., Del Tredici, K., Rüb, U., de Vos, R.A.I., Jansen Steur, E.N.H., Braak, E., 2003. Staging of brain pathology related to sporadic Parkinson's disease. Neurobiol. Aging 24, 197-211.

Braak, H., Rüb, U., Jansen Steur, E.N.H., Del Tredici, K., de Vos, R.A.I., 2005. Cognitive status correlates with neuropathologic stage in Parkinson disease. Neurology 64, 1404-1410.

Brundin, P., Li, J.-Y., Holton, J.L., Lindvall, O., Revesz, T., 2008. Research in motion: the enigma of Parkinson's disease pathology spread. Nat. Rev. Neurosci. 9, 741-745.

Buchman, A.S., Nag, S., Shulman, J.M., Lim, A.S.P., Vanderhorst, V.G.J.M., Leurgans, S.E., Schneider, J.A., Bennett, D.A., 2012. Locus coeruleus neuron density and parkinsonism in older adults without Parkinson's disease. Mov. Disord. 27, 1625-1631.

Buddhala, C., Loftin, S.K., Kuley, B.M., Cairns, N.J., Campbell, M.C., Perlmutter, J.S., Kotzbauer, P.T., 2015. Dopaminergic, serotonergic, and noradrenergic deficits in Parkinson disease. Ann. Clin. Transl. Neurol. 2, 949-959.

Cash, R., Dennis, T., L'Heureux, R., Raisman, R., Javoy-Agid, F., Scatton, B., 1987. Parkinson's disease and dementia: norepinephrine and dopamine in locus ceruleus. Neurology 37, 42-46.

Chase, T.N., Gordon, E.K., Ng, L.K., 1973. Norepinephrine metabolism in the central nervous system of man: studies using 3-methoxy-4-hydroxyphenylethylene glycol levels in cerebrospinal fluid. J. Neurochem. 21, 581-587.

Dayan, L., Finberg, J.P.M., 2003. L-DOPA increases noradrenaline turnover in central and peripheral 
nervous systems. Neuropharmacology 45, 524-533.

De Deurwaerdère, P., Di Giovanni, G., Millan, M.J., 2016. Expanding the repertoire of L-DOPA's actions: A comprehensive review of its functional neurochemistry. Prog. Neurobiol. In Press. doi:10.1016/j.pneurobio.2016.07.002; E-pub ahead of print.

Deeb, J., Shah, M., Muhammed, N., Gunasekera, R., Gannon, K., Findley, L.J., Hawkes, C.H., 2010. A basic smell test is as sensitive as a dopamine transporter scan: comparison of olfaction, taste and DaTSCAN in the diagnosis of Parkinson's disease. QJM 103, 941-952.

Dekker, A.D., Coppus, A.M.W., Vermeiren, Y., Aerts, T., Van Duijn, C.M., Kremer, B.P., Naudé, P.J.W., Van Dam, D., De Deyn, P.P., 2015. Serum MHPG strongly predicts conversion to Alzheimer's disease in behaviorally characterized subjects with Down syndrome. J. Alzheimer's Dis. 43, 871891.

Delaville, C., Chetrit, J., Abdallah, K., Morin, S., Cardoit, L., De Deurwaerdère, P., Benazzouz, A., 2012. Emerging dysfunctions consequent to combined monoaminergic depletions in parkinsonism. Neurobiol. Dis. 45, 763-773.

Del Tredici, K., Braak, H., 2013. Dysfunction of the locus coeruleus-norepinephrine system and related circuitry in Parkinson's disease-related dementia. J Neurol Neurosurg Psychiatry 84, 774-783.

Del Tredici, K., Braak, H., 2012. Spinal cord lesions in sporadic Parkinson's disease. Acta Neuropathol. $124,643-664$.

Del Tredici, K., Rüb, U., De Vos, R. a I., Bohl, J.R.E., Braak, H., 2002. Where does parkinson disease pathology begin in the brain? J. Neuropathol. Exp. Neurol. 61, 413-426.

Dickson, D.W., Fujishiro, H., DelleDonne, A., Menke, J., Ahmed, Z., Klos, K.J., Josephs, K.A., Frigerio, R., Burnett, M., Parisi, J.R., Ahlskog, J.E., 2008. Evidence that incidental Lewy body disease is pre-symptomatic Parkinson's disease. Acta Neuropathol. 115, 437-444.

Doty, R.L., 2012. Olfactory dysfunction in Parkinson disease. Nat. Rev. Neurol. 8, 329-339.

Doty, R.L., Deems, D.A., Stellar, S., 1988a. Olfactory dysfunction in parkinsonism: a general deficit 
unrelated to neurologic signs, disease stage, or disease duration. Neurology 38, 1237-1244.

Doty, R.L., Ferguson-Segall, M., Lucki, I., Kreider, M., 1988b. Effects of intrabulbar injections of 6hydroxydopamine on ethyl acetate odor detection in castrate and non-castrate male rats. Brain Res. 444, 95-103.

Espay, A.J., Dwivedi, A.K., Payne, M., Gaines, L., Vaughan, J.E., Maddux, B.N., Slevin, J.T., Gartner, M., Sahay, A., Revilla, F.J., Duker, A.P., Shukla, R., 2011. Methylphenidate for gait impairment in Parkinson disease: a randomized clinical trial. Neurology 76, 1256-1262.

Espay, A.J., Lewitt, P.A., Kaufmann, H., 2014. Norepinephrine deficiency in Parkinson's disease: The case for noradrenergic enhancement. Mov. Disord. 29, 1710-1719.

Faggiani, E., Benazzouz, A., 2016. Deep brain stimulation of the subthalamic nucleus in Parkinson's disease: from history to the interaction with the monoaminergic systems. Prog. Neurobiol. In Press. doi:10.1016/j.pneurobio.2016.07.003; E-pub ahead of print.

Fischer, A.F., Matera, K.M., 2015. Stabilization of alpha-synuclein oligomers in vitro by the neurotransmitters, dopamine and norepinephrine: the effect of oxidized catecholamines. Neurochem. Res. 40, 1341-1349.

Foote, S.L., Bloom, F.E., Aston-Jones, G., 1983. Nucleus locus ceruleus: new evidence of anatomical and physiological specificity. Physiol. Rev. 63, 844-914.

Foster, N.L., Newman, R.P., LeWitt, P.A., Gillespie, M.M., Larsen, T.A., Chase, T.N., 1984. Peripheral beta-adrenergic blockade treatment of parkinsonian tremor. Ann. Neurol. 16, 505-508.

Fukada, K., Endo, T., Yokoe, M., Hamasaki, T., Hazama, T., Sakoda, S., 2013. L-threo-3,4dihydroxyphenylserine (L-DOPS) co-administered with entacapone improves freezing of gait in Parkinson's disease. Med. Hypotheses 80, 209-212.

German, D.C., Manaye, K.F., White, C.L., Woodward, D.J., McIntire, D.D., Smith, W.K., Kalaria, R.N., Mann, D.M., 1992. Disease-specific patterns of locus coeruleus cell loss. Ann. Neurol. 32, 667676.

Goldstein, D.S., Holmes, C., Li, S.T., Bruce, S., Metman, L. V., Cannon, R.O. 3rd, 2000. Cardiac 
sympathetic denervation in Parkinson disease. Ann. Intern. Med. 133, 338-347.

Goldstein, D.S., Jinsmaa, Y., Sullivan, P., Holmes, C., Kopin, I.J., Sharabi, Y., 2016. Comparison of monoamine oxidase inhibitors in decreasing production of the autotoxic dopamine metabolite 3,4-dihydroxyphenylacetaldehyde in PC12 cells. J. Pharmacol. Exp. Ther. 356, 483-492.

Hakusui, S., Yasuda, T., Yanagi, T., Tohyama, J., Hasegawa, Y., Koike, Y., Hirayama, M., Takahashi, A., 1994. A radiological analysis of heart sympathetic functions with meta[123I]iodobenzylguanidine in neurological patients with autonomic failure. J. Auton. Nerv. Syst. 49, 81-84.

Halliday, G.M., Lees, A., Stern, M., 2011. Milestones in Parkinson's disease - clinical and pathologic features. Mov. Disord. 26, 1015-1021.

Hauser, R.A., Isaacson, S., Lisk, J.P., Hewitt, L.A., Rowse, G., 2015. Droxidopa for the short-term treatment of symptomatic neurogenic orthostatic hypotension in Parkinson's disease (nOH306B). Mov. Disord. 30, 646-654.

Hawkes, C.H., Del Tredici, K., Braak, H., 2010. A timeline for Parkinson's disease. Park. Relat. Disord. $16,79-84$.

Herbert, M.K., Aerts, M.B., Kuiperij, H.B., Claassen, J.A.H.R., Spies, P.E., Esselink, R.A.J., Bloem, B.R., Verbeek, M.M., 2014. Addition of MHPG to Alzheimer's disease biomarkers improves differentiation of dementia with Lewy bodies from Alzheimer's disease but not other dementias. Alzheimer's Dement. 10, 448-455.

Jankovic, J., 2008. Parkinson's disease : clinical features and diagnosis. Neurol Neurosurg Psychiatry 79, 368-376.

Jones, B.E., 2004. Activity, modulation and role of basal forebrain cholinergic neurons innervating the cerebral cortex. Prog Brain Res 145, 157-169.

Kaufmann, H., Freeman, R., Biaggioni, I., Low, P., Pedder, S., Hewitt, L.A., Mauney, J., Feirtag, M., Mathias, C.J., 2014. Droxidopa for neurogenic orthostatic hypotension: a randomized, placebocontrolled, phase 3 trial. Neurology 83, 328-335. 
Kaufmann, H., Nahm, K., Purohit, D., Wolfe, D., 2004. Autonomic failure as the initial presentation of Parkinson disease and dementia with Lewy bodies. Neurology 63, 1093-1095.

Kaufmann, H., Norcliffe-Kaufmann, L., Palma, J.-A., 2015. Droxidopa in neurogenic orthostatic hypotension. Expert Rev. Cardiovasc. Ther. 13, 875-891.

Kessler, J.A., Fenstermacher, J.D., Patlak, C.S., 1976. 3-methoxy-4-hydroxyphenylethyleneglycol (MHPG) transport from the spinal cord during spinal subarachnoid perfusion. Brain Res. 102, 131-141.

Kuhar, M.J., Minneman, K., Muly, E.C., 2006. Catecholamines, in: Siegel, G.J. (Ed.), Basic Neurochemistry: Molecular, Cellular and Medical Aspects. Elsevier, Amsterdam, pp. 211-225.

Lee, P.H., Yeo, S.H., Kim, H.J., Youm, H.Y., 2006. Correlation between cardiac 123I-MIBG and odor identification in patients with Parkinson's disease and multiple system atrophy. Mov. Disord. 21, 1975-1977.

LeWitt, P.A., Hauser, R.A., Lu, M., Nicholas, A.P., Weiner, W., Coppard, N., Leinonen, M., Savola, J.M., 2012. Randomized clinical trial of fipamezole for dyskinesia in Parkinson disease (FJORD study). Neurology 79, 163-169.

Marsh, L., Biglan, K., Gerstenhaber, M., Williams, J.R., 2009. Atomoxetine for the treatment of executive dysfunction in Parkinson's disease: a pilot open-label study. Mov Disord 24, 277-282.

Mavridis, M., Degryse, A., Lategan, A., Marien, M., Colpaert, F., 1991. Effects of locus coeruleus lesions on parkinsonian signs, striatal dopamine and substantia nigra cell loss after 1-methyl-4phenyl-1,2,3,6-tetrahydropyridine in monkeys: a possible role for the locus coeruleus in the progression of Parkinson's disease. Neuroscience 41, 507-523.

McGaughy, J., Ross, R.S., Eichenbaum, H., 2008. Noradrenergic, but not cholinergic, deafferentation of prefrontal cortex impairs attentional set-shifting. Neuroscience 153, 63-71.

McKeith, I.G., Dickson, D.W., Lowe, J., Emre, M., O’Brien, J.T., Feldman, H., Cummings, J., Duda, J.E., Lippa, C., Perry, E.K., Aarsland, D., Arai, H., Ballard, C.G., Boeve, B., Burn, D.J., Costa, D., Del Ser, T., Dubois, B., Galasko, D., Gauthier, S., Goetz, C.G., Gomez-Tortosa, E., Halliday, G., Hansen, 
L.A., Hardy, J., Iwatsubo, T., Kalaria, R.N., Kaufer, D., Kenny, R.A., Korczyn, A., Kosaka, K., Lee, V.M.Y., Lees, A., Litvan, I., Londos, E., Lopez, O.L., Minoshima, S., Mizuno, Y., Molina, J.A., Mukaetova-Ladinska, E.B., Pasquier, F., Perry, R.H., Schulz, J.B., Trojanowski, J.Q., Yamada, M., 2005. Diagnosis and management of dementia with Lewy bodies: Third report of the DLB consortium. Neurology 65, 1863-1872.

More, S.V., Kumar, H., Kim, I.S., Song, S.Y., Choi, D.K., 2013. Cellular and molecular mediators of neuroinflammation in the pathogenesis of Parkinson's disease. Mediators Inflamm. 2013, 952375.

Moreau, C., Delval, A., Defebvre, L., Dujardin, K., Duhamel, A., Petyt, G., Vuillaume, I., Corvol, J.C., Brefel-Courbon, C., Ory-Magne, F., Guehl, D., Eusebio, A., Fraix, V., Saulnier, P.J., LaghaBoukbiza, O., Durif, F., Faighel, M., Giordana, C., Drapier, S., Maltête, D., Tranchant, C., Houeto, J.L., Debû, B., Sablonniere, B., Azulay, J.P., Tison, F., Rascol, O., Vidailhet, M., Destée, A., Bloem, B.R., Bordet, R., Devos, D., 2012. Methylphenidate for gait hypokinesia and freezing in patients with Parkinson's disease undergoing subthalamic stimulation: a multicentre, parallel, randomised, placebo-controlled trial. Lancet Neurol. 11, 589-596.

Nakamura, T., Hirayama, M., Hara, T., Hama, T., Watanabe, H., Sobue, G., 2011. Does cardiovascular autonomic dysfunction contribute to fatigue in Parkinson's disease? Mov. Disord. 26, 18691874.

O’Donnell, J., Zeppenfeld, D., McConnell, E., Pena, S., Nedergaard, M., 2012. Norepinephrine: A neuromodulator that boosts the function of multiple cell types to optimize CNS performance. Neurochem. Res. 37, 2496-2512.

Ogawa, N., Kuroda, H., Yamamoto, M., Nukina, I., Ota, Z., 1984. Improvement in freezing phenomenon of Parkinson's disease after DL-threo-3, 4-dihydroxyphenylserine. Acta Med. Okayama 38, 301-304.

Pamphlett, R., 2014. Uptake of environmental toxicants by the locus ceruleus: A potential trigger for neurodegenerative, demyelinating and psychiatric disorders. Med. Hypotheses 82, 97-104. 
Parvizi, J., Van Hoesen, G.W., Damasio, A., 2001. The selective vulnerability of brainstem nuclei to Alzheimer's disease. Ann. Neurol. 49, 53-66.

Pintor, L., Baillès, E., Valldeoriola, F., Tolosa, E., Martí, M.J., De Pablo, J., 2006. Response to 4-month treatment with reboxetine in Parkinson's disease patients with a major depressive episode. Gen. Hosp. Psychiatry 28, 59-64.

Pringsheim, T., Jette, N., Frolkis, A., Steeves, T.D.L., 2014. The prevalence of Parkinson's disease: a systematic review and meta-analysis. Mov. Disord. 29, 1583-90.

Rascol, O., Arnulf, I., Peyro-Saint Paul, H., Brefel-Courbon, C., Vidailhet, M., Thalamas, C., Bonnet, A.M., Descombes, S., Bejjani, B., Fabre, N., Montastruc, J.L., Agid, Y., 2001. Idazoxan, an alpha-2 antagonist, and L-DOPA-induced dyskinesias in patients with Parkinson's disease. Mov. Disord. $16,708-713$.

Rascol, O., Brooks, D.J., Melamed, E., Oertel, W., Poewe, W., Stocchi, F., Tolosa, E.; LARGO study group, 2005. Rasagiline as an adjunct to levodopa in patients with Parkinson's disease and motor fluctuations (LARGO, Lasting effect in Adjunct therapy with Rasagiline Given Once daily, study): a randomised, double-blind, parallel-group trial. Lancet 365, 947-954.

Rascol, O., Fitzer-Attas, C.J., Hauser, R., Jankovic, J., Lang, A., Langston, J.W., Melamed, E., Poewe, W., Stocchi, F., Tolosa, E., Eyal, E., Weiss, Y.M., Olanow, C.W., 2011. A double-blind, delayed-start trial of rasagiline in Parkinson's disease (the ADAGIO study): prespecified and post-hoc analyses of the need for additional therapies, changes in UPDRS scores, and non-motor outcomes. Lancet Neurol. 10, 415-423.

Richard, I.H., McDermott, M.P., Kurlan, R., Lyness, J.M., Como, P.G., Pearson, N., Factor, S.A., Juncos, J., Ramos, C.S., Brodsky, M., Manning, C., Marsh, L., Shulman, L., Fernandez, H.H., Black, K.J., Panisset, M., Christine, C.W., Jiang, W., Singer, C., Horn, S., Pfeiffer, R., Rottenberg, D., Slevin, J., Elmer, L., Press, D., Hyson, H.C., McDonald, W., 2012. A randomized, double-blind, placebocontrolled trial of antidepressants in Parkinson disease. Neurology 78, 1229-1236.

Riekkinen, M., Jäkälä, P., Kejonen, K., Riekkinen, P. Jr., 1999. The alpha2 agonist, clonidine, improves 
spatial working memory performance in Parkinson's disease. Neuroscience 92, 983-989.

Robbins, T.W., Arnsten, A.F., 2009. The neuropsychopharmacology of fronto-executive function: monoaminergic modulation. Annu Rev Neurosci 32, 267-287.

Rommelfanger, K.S., Weinshenker, D., 2007. Norepinephrine: The redheaded stepchild of Parkinson's disease. Biochem. Pharmacol. 74, 177-190.

Samuels, E.R., Szabadi, E., 2008. Functional neuroanatomy of the noradrenergic locus coeruleus: its roles in the regulation of arousal and autonomic function part $\mathrm{N}$ : physiological and pharmacological manipulations and pathological alterations of locus coeruleus activity in humans. Curr. Neuropharmacol. 6, 254-285.

Sara, S.J., 2009. The locus coeruleus and noradrenergic modulation of cognition. Nat. Rev. Neurosci. $10,211-223$.

Seidel, K., Mahlke, J., Siswanto, S., Krüger, R., Heinsen, H., Auburger, G., Bouzrou, M., Grinberg, L., Wicht, H., Korf, H.-W., den Dunnen, W., Rüb, U., 2015. The brainstem pathologies of Parkinson's disease and dementia with Lewy bodies. Brain Pathol. 25, 121-135.

Sharma, R.P., Javaid, J.I., Faull, K., Davis, J.M., Janicak, P.G., 1994. CSF and plasma MHPG, and the CSF MHPG index: Pretreatment levels in diagnostic groups and response to somatic treatments. Psychiatry Res. 51, 51-60.

Slaets, S., Van Acker, F., Versijpt, J., Hauth, L., Goeman, J., Martijn, J.-J., De Deyn, P.P., Engelborghs, S., 2015. Diagnostic value of MIBG cardiac scintigraphy for differential dementia diagnosis. Int. J. Geriatr. Psychiatry 30, 864-869.

Smith, K.M., Eyal, E., Weintraub, D.; ADAGIO Investigators, 2015. Combined rasagiline and antidepressant use in Parkinson disease in the ADAGIO study: effects on nonmotor symptoms and tolerability. JAMA Neurol 72, 88-95.

Spillantini, M.G., Crowther, R.A., Jakes, R., Hasegawa, M., Goedert, M., 1998. Alpha-synuclein in filamentous inclusions of Lewy bodies from Parkinson's disease and dementia with lewy bodies. Proc. Natl. Acad. Sci. U. S. A. 95, 6469-6473. 
Sterpenich, V., D’Argembeau, A., Desseilles, M., Balteau, E., Albouy, G., Vandewalle, G., Degueldre, C., Luxen, A., Collette, F., Maquet, P., 2006. The locus ceruleus is involved in the successful retrieval of emotional memories in humans. J. Neurosci. 26, 7416-7423.

Stewart, J.M., 2012. Mechanisms of sympathetic regulation in orthostatic intolerance. J. Appl. Physiol. 1659-1668.

Szot, P., White, S.S., Greenup, J.L., Leverenz, J.B., Peskind, E.R., Raskind, M.A., 2006. Compensatory changes in the noradrenergic nervous system in the locus ceruleus and hippocampus of postmortem subjects with Alzheimer's disease and dementia with Lewy bodies. J Neurosci 26, 467-478.

Takatsu, H., Nishida, H., Matsuo, H., Watanabe, S., Nagashima, K., Wada, H., Noda, T., Nishigaki, K., Fujiwara, H., 2000. Cardiac sympathetic denervation from the early stage of Parkinson's disease: clinical and experimental studies with radiolabeled MIBG. J Nucl Med 41, 71-77.

Taylor, T.N., Alter, S.P., Wang, M., Goldstein, D.S., Miller, G.W., 2014. Reduced vesicular storage of catecholamines causes progressive degeneration in the locus ceruleus. Neuropharmacology 76, 97-105.

Tong, J., Hornykiewicz, O., Kish, S.J., 2006. Inverse relationship between brain noradrenaline level and dopamine loss in Parkinson disease: a possible neuroprotective role for noradrenaline. Arch. Neurol. 63, 1724-1728.

Trillo, L., Das, D., Hsieh, W., Medina, B., Moghadam, S., Lin, B., Dang, V., Sanchez, M.M., De Miguel, Z., Ashford, J.W., Salehi, A., 2013. Ascending monoaminergic systems alterations in Alzheimer's disease. Translating basic science into clinical care. Neurosci. Biobehav. Rev. 37, 1363-1379.

Vazey, E.M., Aston-Jones, G., 2012. The emerging role of norepinephrine in cognitive dysfunctions of Parkinson's disease. Front. Behav. Neurosci. 6, 48.

Vermeiren, Y., Janssens, J., Aerts, T., Martin, J.-J., Sieben, A., Van Dam, D., De Deyn, P.P., 2016. Brain serotonergic and noradrenergic deficiencies in behavioral variant frontotemporal dementia compared to early-onset Alzheimer's disease. J. Alzheimers Dis. 53, 1079-1096. 
Vermeiren, Y., Van Dam, D., Aerts, T., Engelborghs, S., De Deyn, P.P., 2014. Monoaminergic neurotransmitter alterations in postmortem brain regions of depressed and aggressive patients with Alzheimer's disease. Neurobiol. Aging 35, 2691-2700.

Vermeiren, Y., Van Dam, D., Aerts, T., Engelborghs, S., Martin, J.-J., De Deyn, P.P., 2015. The monoaminergic footprint of depression and psychosis in dementia with Lewy bodies compared to Alzheimer's disease. Alzheimers. Res. Ther. 7, 7.

Watanabe, H., leda, T., Katayama, T., Takeda, A., Aiba, I., Doyu, M., Hirayama, M., Sobue, G., 2001. Cardiac (123)I-meta-iodobenzylguanidine (MIBG) uptake in dementia with Lewy bodies: comparison with Alzheimer's disease. J. Neurol. Neurosurg. Psychiatry 70, 781-783.

Weintraub, D., Mavandadi, S., Mamikonyan, E., Siderowf, A.D., Duda, J.E., Hurtig, H.I., Colcher, A., Horn, S.S., Nazem, S., Ten Have, T.R., Stern, M.B., 2010. Atomoxetine for depression and other neuropsychiatric symptoms in Parkinson disease. Neurology 75, 448-455.

Wong, K.K., Muller, M.L.T.M., Kuwabara, H., Studenski, S.A., Bohnen, N.I., 2010. Olfactory loss and nigrostriatal dopaminergic denervation in the elderly. Neurosci. Lett. 484, 163-167. 


\section{TABLES}

Table 1. Clinical correlates of LC-related NE deficiency in PD and related disorders based on its impaired efferent projections

\begin{tabular}{lll}
\hline LC projection target & Clinical correlate & Categorical symptom \\
\hline SNpc - thalamus & $\begin{array}{l}\text { Worsening of parkinsonian symptoms: tremor, } \\
\text { akinesia, freezing of gait }\end{array}$ & Motor features \\
\hline Prefrontal cortex & Impaired working memory and attention deficits & Cognitive disturbances \\
HC - Amygdala & Dysfunctional memory consolidation and \\
& retrieval \\
\hline VTA & Impaired attention, apathy \\
Ventral striatum & Apathy \\
Limbic thalamus - ACC & Depression and anxiety \\
Motor thalamus & $\begin{array}{l}\text { Wakefulness, disrupted sleep-wake cycle } \\
\text { REM sleep behavioral disorder, i.e.: poor REM } \\
\text { VLPAGM - LPT }\end{array}$ & $\begin{array}{l}\text { sleep inhibition (due to ineffective NE activation } \\
\text { of REM-off neurons) }\end{array}$ \\
\hline $\begin{array}{l}\text { Abbreviations: ACC: anterior cingulate cortex; HC: hippocampus; NE: norepinephrine; PD: Parkinson's disease; LC: } \\
\text { locus coeruleus; LPT: lateral pontine tegmentum; SNpc: pars compacta of the substantia nigra; VLPAGM: } \\
\text { ventrolateral periaqueductal grey matter; VTA: ventral tegmental area; Based upon Espay et al. (2014). }\end{array}$
\end{tabular}


Table 2. Overview of completed clinical studies that evaluated various NE-enhancing drugs to improve motor and non-motor manifestations in PD

\begin{tabular}{|c|c|c|c|c|c|}
\hline Target & Study & Drug and dosage & Mechanism of action & Subjects and outcome measures & Results \\
\hline \multicolumn{6}{|c|}{ Motor manifestations } \\
\hline \multirow[t]{3}{*}{$\mathrm{NOH}$} & Kaufmann et al., 2014 & $\begin{array}{l}\text { Droxidopa } \\
-100 \text { to } 600 \mathrm{mg}, 3 \text { times a } \\
\text { day }\end{array}$ & NE prodrug & $\begin{array}{l}\text {-111 PD subjects out of a total group of } 162 \\
\text { with various diagnoses (PAF, MSA, NAN) } \\
\text {-Patient's self-ratings on Orthostatic } \\
\text { Hypotension Questionnaire }\end{array}$ & $\begin{array}{l}\text { Objective/subjective improvement } \\
\text { of } \mathrm{NOH} \text { at } 7 \text { days }\end{array}$ \\
\hline & Biaggioni et al., 2015 & $\begin{array}{l}\text { Droxidopa } \\
-100 \text { to } 600 \mathrm{mg}, 3 \text { times a } \\
\text { day }\end{array}$ & NE prodrug & $\begin{array}{l}\text {-72 PD subjects out of a total group of } 181 \\
\text { with various diagnoses (PAF, MSA, NAN) } \\
\text {-Orthostatic hypotension, dizziness, } \\
\text { lightheadedness scores (patient's self-ratings) }\end{array}$ & $\begin{array}{l}\text { Improvement of } \mathrm{NOH} \text { and daily } \\
\text { activities }\end{array}$ \\
\hline & Hauser et al., 2015 & $\begin{array}{l}\text { Droxidopa } \\
-100 \text { to } 600 \mathrm{mg}, 3 \text { times a } \\
\text { day }\end{array}$ & NE prodrug & $\begin{array}{l}\text { - } 171 \text { PD patients with } \mathrm{NOH} \\
\text {-Patient's self-ratings on Orthostatic } \\
\text { Hypotension Questionnaire }\end{array}$ & $\begin{array}{l}\text { Objective/subjective short-term } \\
\text { improvement of } \mathrm{NOH}\end{array}$ \\
\hline \multirow[t]{4}{*}{ FOG } & Ogawa et al., 1984 & $\begin{array}{l}\text { Droxidopa treatment for } \\
10 \text { days (dosage unknown) }\end{array}$ & NE prodrug & $\begin{array}{l}\text { Case study; } 1 \text { PD patient with FOG, treated } \\
\text { with levodopa and benserazide }\end{array}$ & $\begin{array}{l}\text { Immediate improvement of } \\
\text { levodopa-resistant FOG and } \\
\text { dysarthria; } 127.5 \% \text { increase of CSF } \\
\text { MHPG levels compared to pre- } \\
\text { treatment stage }\end{array}$ \\
\hline & Espay et al., 2011 & $\begin{array}{l}\text { Methylphenidate } \\
-5 \text { to } 810 \mathrm{mg} \text { tablets a day } \\
\text {-maximum dose of } \\
1 \mathrm{mg} / \mathrm{kg} / \text { day divided over } 3 \\
\text { doses }\end{array}$ & & $\begin{array}{l}\text {-27 PD subjects with moderate gait } \\
\text { impairment } \\
\text {-Change in gait composite score + changes in } \\
\text { motor function (UPDRS scores) }\end{array}$ & $\begin{array}{l}\text { No observed improvements } \\
\text { regarding gait; even tendency } \\
\text { towards worsened measures of } \\
\text { motor function and sleepiness; } \\
\text { marginal improvement of } \\
\text { depression }\end{array}$ \\
\hline & Moreau et al., 2012 & $\begin{array}{l}\text { STN-DBS combined with } \\
\text { methylphenidate } \\
-4 \text { to } 810 \mathrm{mg} \text { tablets a day } \\
\text {-maximum dose of } \\
1 \mathrm{mg} / \mathrm{kg} / \text { day divided over } 3 \\
\text { doses }\end{array}$ & $\begin{array}{l}\text { Neurostimulation of } \\
\text { STN and NDRI }\end{array}$ & $\begin{array}{l}\text {-81 PD patients without dementia } \\
\text {-Changes in stand-walk-sit tests }\end{array}$ & $\begin{array}{l}\text { Improvement of gait hypokinesia } \\
\text { and freezing after } \\
\text { methylphenidate in advanced PD } \\
\text { patients receiving STN-DBS }\end{array}$ \\
\hline & Fukada et al., 2013 & $\begin{array}{l}\text { Droxidopa and entacapone } \\
\text {-both } 300 \text { up to } 600 \mathrm{mg} \text { per } \\
\text { day }\end{array}$ & $\begin{array}{l}\text { NE prodrug combined } \\
\text { with a COMT inhibitor }\end{array}$ & $\begin{array}{l}\text {-16 PD patients with FOG } \\
\text {-FOG severity evaluated by visual analogue } \\
\text { scale }\end{array}$ & $\begin{array}{l}\text { Only patients that received the } \\
\text { combination therapy }(n=6) \text { showed } \\
\text { significant improvement of FOG; } \\
\text { these were levodopa-resistant FOG } \\
\text { patients }\end{array}$ \\
\hline
\end{tabular}


Table 2. Continued

\begin{tabular}{|c|c|c|c|c|c|}
\hline Target & Study & Drug and dosage & Mechanism of action & Subjects and outcome measures & Results \\
\hline $\begin{array}{l}\text { Resting and acting } \\
\text { tremor }\end{array}$ & Foster et al., 1984 & $\begin{array}{l}\text { Nadolol } \\
-80 \text { to } 320 \mathrm{mg} / \text { day for } 6 \\
\text { weeks }\end{array}$ & $\begin{array}{l}\text { Non-selective } \\
\text { peripheral } \beta \text {-blocker } \\
\text { (both } \beta_{1 / 2} \text { ) }\end{array}$ & $\begin{array}{l}-8 \text { idiopathic PD patients with well-controlled } \\
\text { motor symptoms other than tremor } \\
\text {-Accelerometer readings }\end{array}$ & $\begin{array}{l}\text { Improvement of resting tremor by } \\
54 \% \text {, postural tremor by } 32 \% \text {, and, } \\
\text { intention tremor by } 54 \%\end{array}$ \\
\hline \multirow[t]{2}{*}{$\begin{array}{l}\text { L-DOPA-induced } \\
\text { dyskinesia }\end{array}$} & Rascol et al., 2001 & $\begin{array}{l}\text { Idazoxan } \\
\text {-single oral dose }(10,20 \text { or } \\
40 \mathrm{mg})\end{array}$ & $\begin{array}{l}\text { Selective } \alpha_{2-} \\
\text { adrenoreceptor } \\
\text { antagonist }\end{array}$ & $\begin{array}{l}\text {-18 PD subjects on levodopa } \\
\text {-UPDRS motor score (part III+IV) to monitor } \\
\text { dyskinesia; patients were videotaped } \\
\text { (retrospective assessment) }\end{array}$ & $\begin{array}{l}\text { After } 20 \mathrm{mg} \text { dosage, there was } \\
\text { significant improvement of } \\
\text { dyskinesia ( } 40 \% \text { ); no concomitant } \\
\text { deterioration in antiparkinsonian } \\
\text { response to L-DOPA }\end{array}$ \\
\hline & LeWitt et al., 2012 & $\begin{array}{l}\text { Fipamezole } \\
\text {-a } 30,60 \text { or } 90 \mathrm{mg} \text { tablet } 3 \\
\text { times a day for max. } 28 \\
\text { days }\end{array}$ & $\begin{array}{l}\text { Selective } \alpha_{2^{-}} \\
\text {adrenoreceptor } \\
\text { antagonist }\end{array}$ & $\begin{array}{l}\text { - } 115 \text { PD subjects in US ( } 25 \text { centers) and } 64 \text { PD } \\
\text { subjects in India ( } 7 \text { centers); all on levodopa } \\
\text {-UPDRS and LIDS scores }\end{array}$ & $\begin{array}{l}\text { Only US patients improved after } \\
\text { receiving } 90 \mathrm{mg} 3 \mathrm{x} / \text { day (reduced } \\
\text { dyskinesia); however, no observed } \\
\text { improvements in total population }\end{array}$ \\
\hline \multicolumn{6}{|l|}{ Non-motor manifestations } \\
\hline \multirow[t]{4}{*}{ Depression } & Pintor et al., 2006 & $\begin{array}{l}\text { Reboxetine } \\
\text {-daily dosage of } 2-4 \mathrm{mg} \\
\text { during } 4 \text { months (adjusted if } \\
\text { necessary) }\end{array}$ & NRI & $\begin{array}{l}\text {-17 PD patients with MDD } \\
\text {-HAM-D and UPDRS scores }\end{array}$ & $\begin{array}{l}\text { Progressive improvement of } \\
\text { depressive symptoms; no change } \\
\text { in motor symptoms (UPDRS } \\
\text { scores) after } 4 \text { months }\end{array}$ \\
\hline & Weintraub et al., 2010 & $\begin{array}{l}\text { Atomoxetine } \\
-40 \text { or } 80 \mathrm{mg} / \text { day, } 8 \text { weeks }\end{array}$ & & $\begin{array}{l}\text {-55 PD subjects with a score } \geq 22 \text { on the IDS-C } \\
\text {-primary: IDS-C (depression) and CGI-I scores; } \\
\text { secondary: MMSE and ESS scores }\end{array}$ & $\begin{array}{l}\text { No observed improvement of } \\
\text { depressive symptoms, but } \\
\text { improvement of secondary } \\
\text { outcome measures (global } \\
\text { cognition and sleepiness) }\end{array}$ \\
\hline & Richard et al., 2012 & $\begin{array}{l}\text { Venlafaxine } \\
\text {-max. } 225 \mathrm{mg} \text { a day for } 12 \\
\text { weeks }\end{array}$ & SNRI & $\begin{array}{l}-115 \text { PD subjects enrolled at } 20 \text { sites } \\
\text {-HAM-D scores }\end{array}$ & $\begin{array}{l}\text { Significant improvement of } \\
\text { depression (- } 6.2 \text { points on HAM- } \\
\text { D); no motor effects }\end{array}$ \\
\hline & Bonuccelli et al., 2012 & $\begin{array}{l}\text { Duloxetine } \\
\text {-60mg once daily for } 12 \\
\text { weeks }\end{array}$ & SNRI & $\begin{array}{l}\text {-151 PD patients with MDD } \\
\text {-HAM-D and PDQ scores }\end{array}$ & $\begin{array}{l}\text { Significant improvement of HAM-D } \\
\text { (-11.4 points) and PDQ scores (-7.7 } \\
\text { points; quality of life) }\end{array}$ \\
\hline Executive dysfunction & Marsh et al., 2009 & $\begin{array}{l}\text { Atomoxetine } \\
\text {-flexible dose (25- } \\
\text { 100mg/day), } 8 \text { weeks }\end{array}$ & NRI & $\begin{array}{l}\text {-12 PD patients with disabling executive } \\
\text { dysfunction (ED) } \\
\text { - CGI-I, FrSBe and CAARS scores }\end{array}$ & $\begin{array}{l}\text { Improvement of all ED-related } \\
\text { scores, but adverse events (GI } \\
\text { disturbances, hypomania) }\end{array}$ \\
\hline
\end{tabular}


Table 2. Continued

\begin{tabular}{|c|c|c|c|c|c|}
\hline Target & Study & Drug and dosage & Mechanism of action & Subjects and outcome measures & Results \\
\hline Global cognition & Weintraub et al., 2010 & $\begin{array}{l}\text { Atomoxetine } \\
-40 \text { or } 80 \mathrm{mg} / \text { day, } 8 \text { weeks }\end{array}$ & NRI & $\begin{array}{l}\text {-55 PD subjects with a score } \geq 22 \text { on the IDS-C } \\
\text {-primary: IDS-C and CGI-I scores; secondary: } \\
\text { MMSE (global cognition) and ESS (daytime } \\
\text { sleepiness) scores }\end{array}$ & $\begin{array}{l}\text { Significant improvement of } \\
\text { secondary outcome measures } \\
\text { (MMSE = +1.31 point; EES }=-2.9 \\
\text { points) }\end{array}$ \\
\hline $\begin{array}{l}\text { Impaired spatial } \\
\text { working memory }\end{array}$ & Riekkinen et al., 1999 & $\begin{array}{l}\text { Clonidine } \\
-0.5 \text { or } 2 \mu \mathrm{g} / \mathrm{kg} \text { per day }\end{array}$ & $\begin{array}{l}\text { Non-selective } \alpha_{2^{-}} \\
\text {adrenoreceptor } \\
\text { agonist }\end{array}$ & $\begin{array}{l}\text {-32 PD patients on dopaminergic medication } \\
\text { (16 mild, } 16 \text { severe) without depression or } \\
\text { dementia: } 27 \text { age-matched controls } \\
\text {-Number of within- and between-search } \\
\text { errors }\end{array}$ & $\begin{array}{l}\text { In mild/severe PD, there was an } \\
\text { improvement in the } 2 \mu \mathrm{g} / \mathrm{kg} \\
\text { treated groups (i.e. decrease of } \\
\text { between-search errors) with } \\
\text { greater total effect in severe PD }\end{array}$ \\
\hline Impaired attention & Bédard et al., 1998 & $\begin{array}{l}\text { Naphtoxazine } \\
-24 \mathrm{mg} / \mathrm{day}, 1 \text { week }\end{array}$ & $\begin{array}{l}\text { Selective } \alpha_{1}{ }^{-} \\
\text {adrenoreceptor } \\
\text { agonist }\end{array}$ & $\begin{array}{l}\text {-9 patients with idiopathic PD on } \\
\text { dopaminergic medication and presence of } \\
\mathrm{MCl} \\
\text {-Neuropsychological tests (e.g. Stroop and } \\
\text { Odd-Man-Out tests, TMT, frontal function) } \\
\text { and evoked potentials }\end{array}$ & $\begin{array}{l}\text { Improvement of } \mathrm{Nd} 1 \text { and } \mathrm{Nd} 2 \\
\text { curves (evoked potentials), } \\
\text { thought to reflect attentional } \\
\text { processes, and, various } \\
\text { neuropsychological tasks }\end{array}$ \\
\hline
\end{tabular}

Green: significant improvements; orange: no observed improvements/differences - no worsening as well; red: worsening of symptoms.

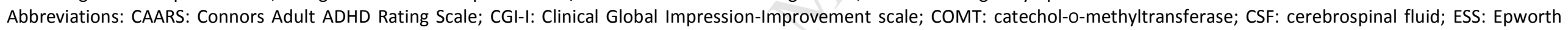

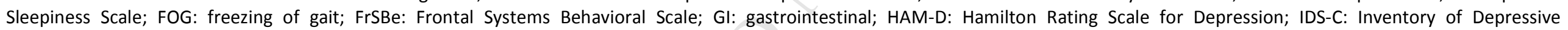

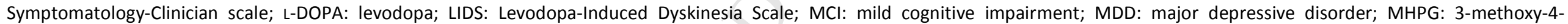

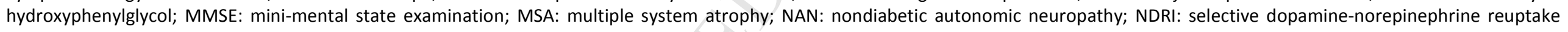

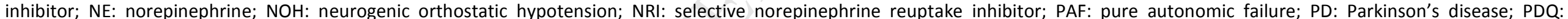

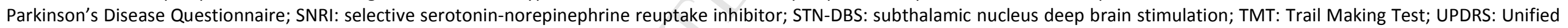
Parkinson's Disease Rating Scale. 


\section{FIGURE LEGENDS}

Fig. 1. Both left and right locus coeruleus (LC) (arrows; size for each: approximately $14.5 \mathrm{~mm}$ in length and $2.5 \mathrm{~mm}$ in thickness) adjacent to the fourth ventricle of a 79 -year old male with a putative, clinical diagnosis of cerebellar atrophy (12\% paraformaldehyde; transverse section at the level of the inferior colliculi). There was an age-related, limited decrease of the number of LC neurons during microscopic examination, but a normal substantia nigra (no depigmentation). The neuropathological diagnosis eventually was that of normal aging changes. Source of figure: archives of the Biobank of the Institute Born-Bunge (IBB), University of Antwerp, Antwerp.

Fig. 2. Formalin-fixed paraffin-embedded section showing $\alpha$-synuclein-positive Lewy bodies and neurites in the dorsal nucleus of the vagus nerve (N. X.); from a 72-year old male with the neuropathological diagnosis of diffuse Lewy body disease and mild Alzheimer pathology. Source of figure: archives of the Biobank of the Institute Born-Bunge (IBB), University of Antwerp, Antwerp.

Fig. 3. Abundant Lewy bodies and neurites in a formalin-fixed paraffin-embedded section of the locus coeruleus (anti-ubiquitin staining); from a 89-year old female with the neuropathological diagnosis of brainstem-predominant dementia with Lewy bodies. Source of figure: archives of the Biobank of the Institute Born-Bunge (IBB), University of Antwerp, Antwerp.

Fig. 4. Depigmented, pale substantia nigra pars compacta from a 68-year old male with the neuropathological diagnosis of Parkinson's disease (12\% paraformaldehyde; transverse section at the level of the superior colliculi). Source of figure: archives of the Biobank of the Institute Born-Bunge (IBB), University of Antwerp, Antwerp. 


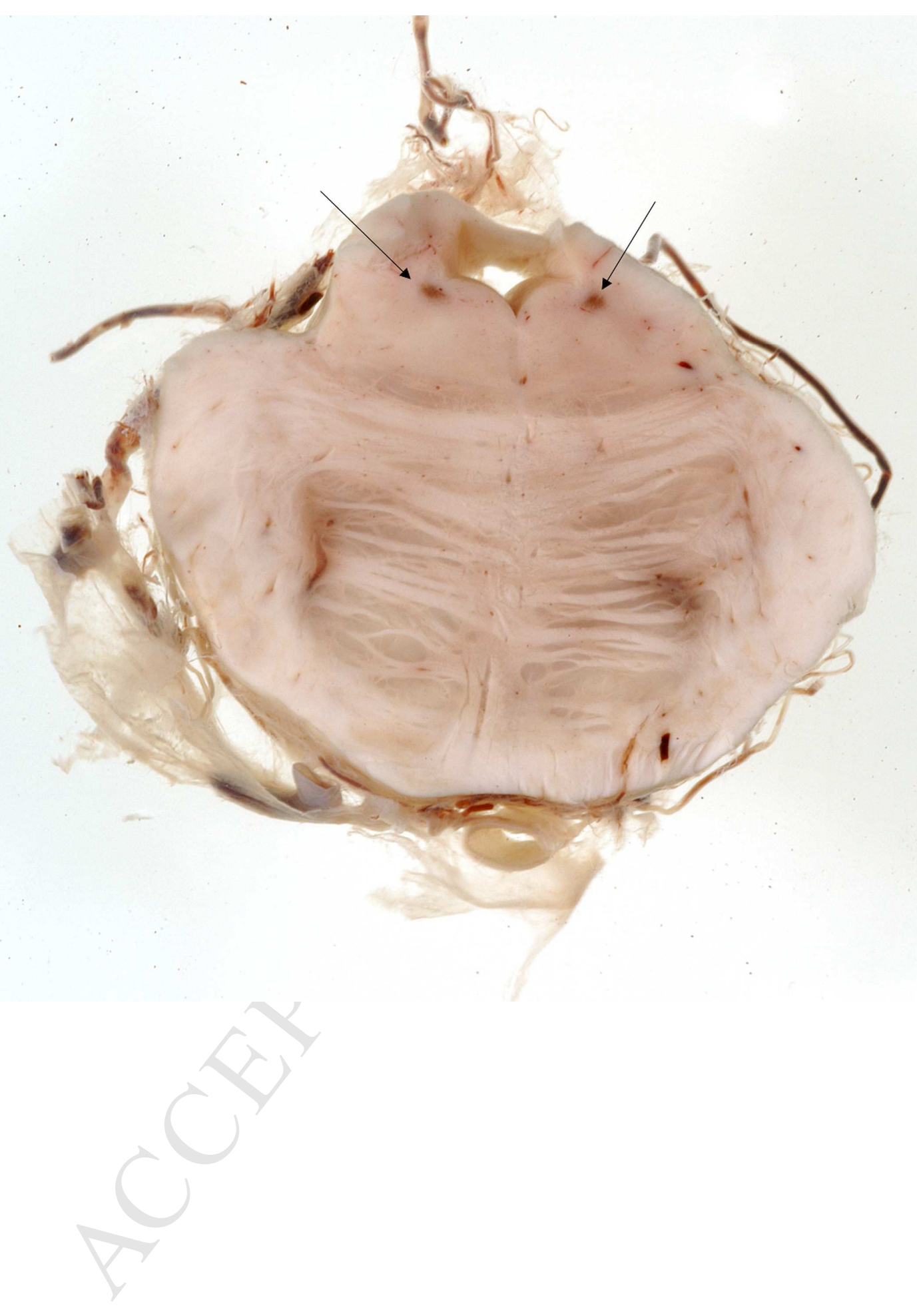




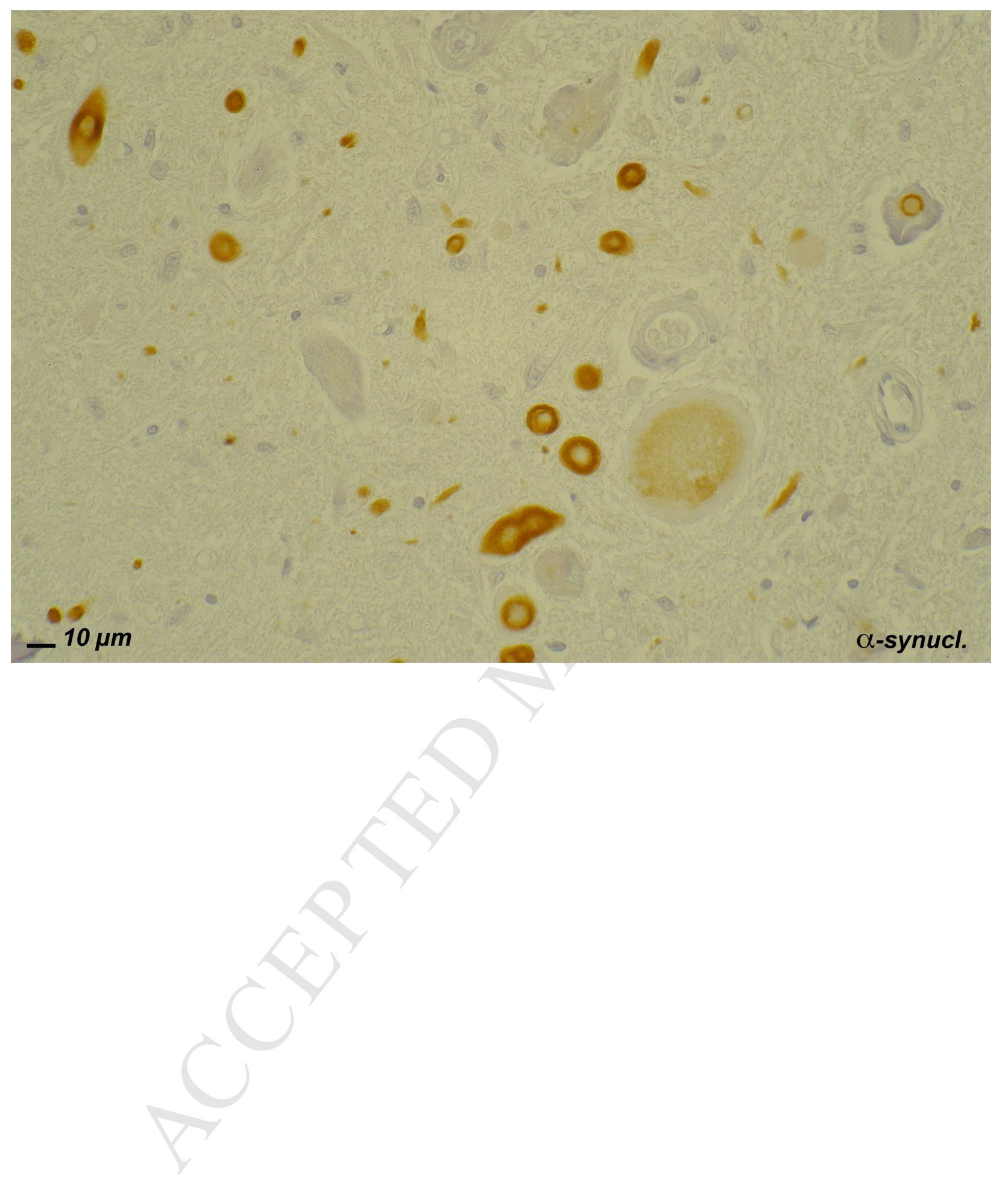




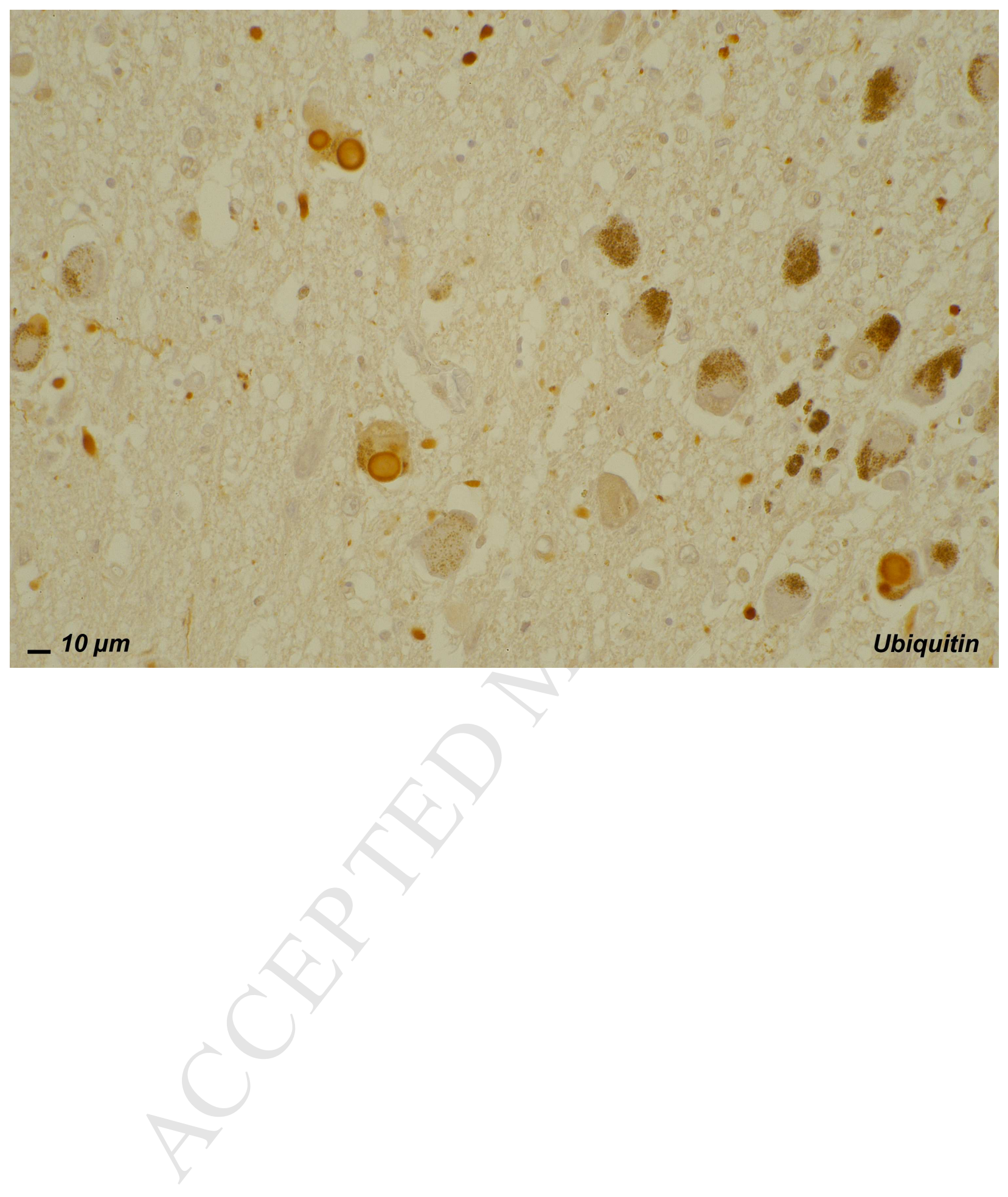




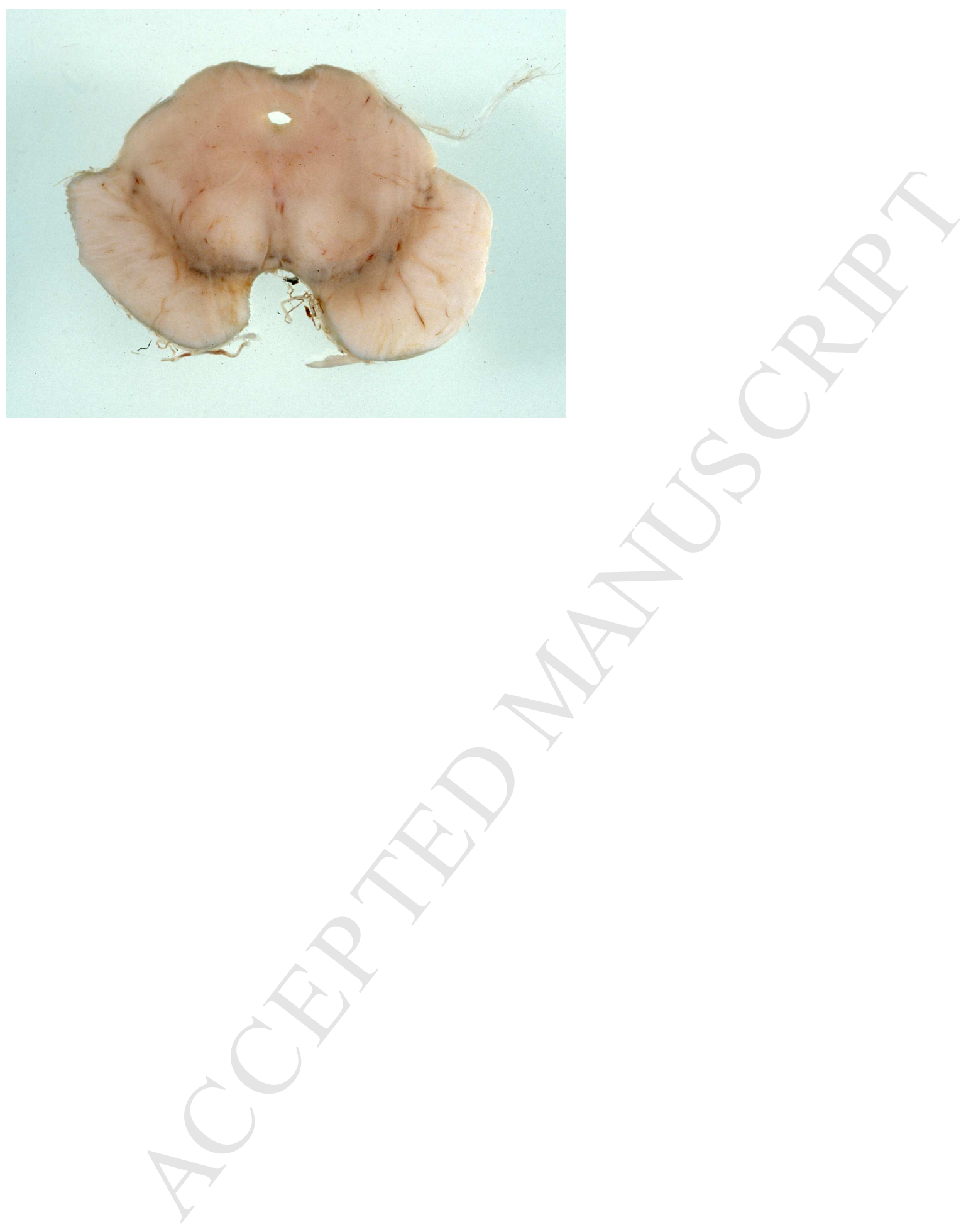


- Parkinson's disease (PD) is characterized by loss of locus coeruleus (LC) neurons

- LC lesioning occurs earlier and to greater extent than that of the substantia nigra

- There is a solid link between an altered LC-norepinephrine (NE) system and dementia

- Peripheral/central MHPG, NE's main metabolite, may serve as an early marker for PD

- Therapeutic strategies enhancing NE signaling may hold great potential to treat PD 